\title{
A Review of Thermal Performance in Multiple Evaporators Loop Heat Pipe
}

\author{
Y. Qu ${ }^{\mathrm{a}, *}$, S.Wang ${ }^{\mathrm{a}}$, Y. Tian ${ }^{\mathrm{b}}$ \\ a School of Chemical Engineering, China University of Petroleum, Qingdao 266580, China \\ b School of Engineering and Sustainable Development, \\ De Montfort University, Leicestershire LE1 9BH, England, UK \\ *Corresponding author, Email: yanqu@upc.edu.cn, Tel: (+86) 532-86983482
}

\begin{abstract}
Multi-evaporator loop heat pipe (ME-LHP), as one of the typical two-phase closed capillary circulation systems, exhibits tremendous potential in applications which involve high heat flux and multi-heat sources, and is especially attractive to spacecraft and electronics packaging thermal control. This paper provides a comprehensive review of ME-LHP research and developments for the past 20 years covering four aspects: design theory, mathematical models, steady-state operational performance and start-up performance. ME-LHP design theory contains three key problems including the number limit for evaporators, sizing of the compensation chamber (CC) and calculation of the working fluid charge. Three peculiar features in steady performance have been discussed, which are the heat load sharing feature, the control rules of the operation temperature among multiple CCs, and the capillary limit of ME-LHP. Two influencing factors of start-up performance have been taken into account, including the required superheat on ME-LHP start-up and the initial fluid distribution in evaporators.
\end{abstract}

Keyword: multiple evaporator loop heat pipe (ME-LHP); thermal performance; heat load sharing; start-up superheat

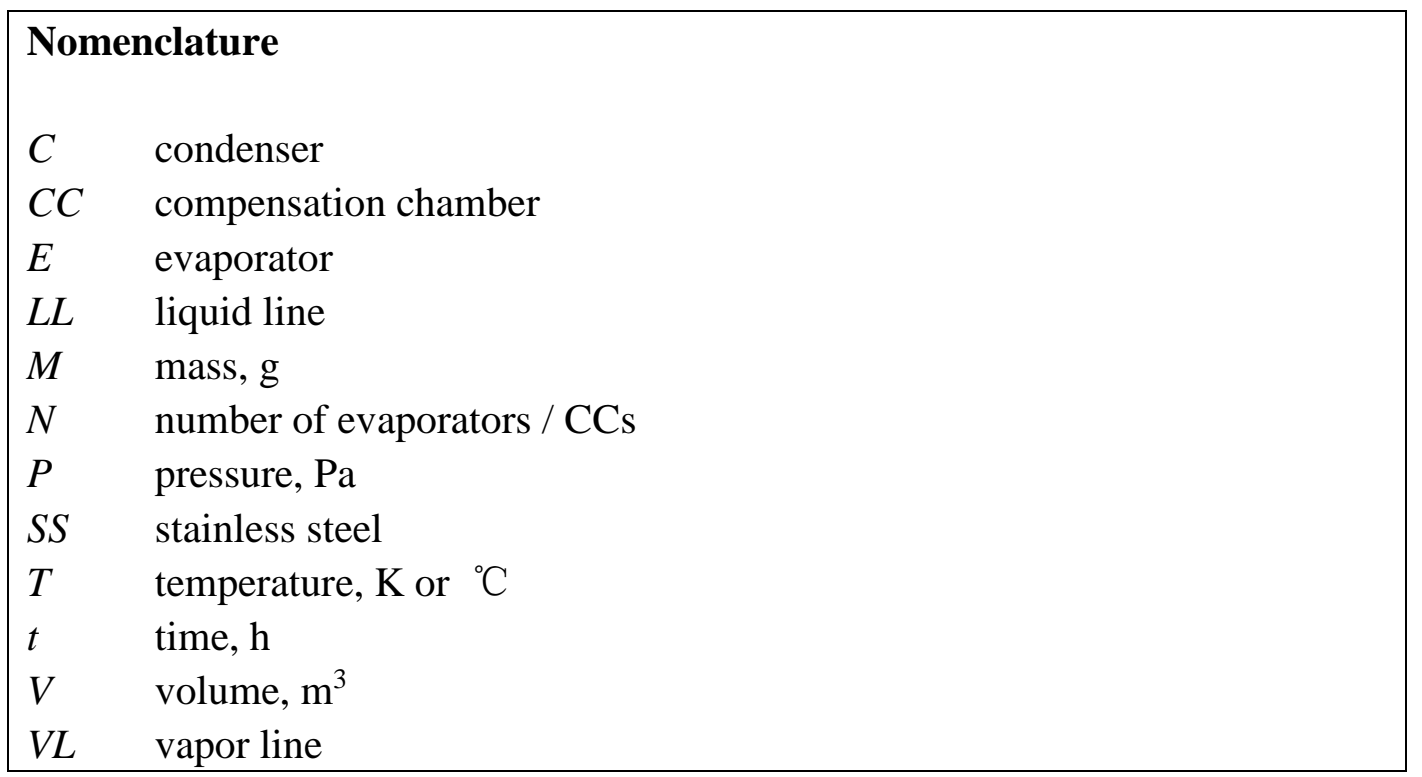




$$
\begin{array}{ll}
\multicolumn{2}{l}{\text { Greek letter }} \\
\alpha & \text { void fraction } \\
\beta & \text { liquid fraction } \\
\varepsilon & \text { porosity } \\
\rho & \text { density, g/cm }{ }^{3} \\
& \\
\text { Subscripts } \\
c & \text { worst cold case } \\
c c & \text { compensation chamber } \\
c o n d & \text { condenser } \\
e & \text { evaporator } \\
g r & \text { vapor groove } \\
h & \text { worst hot case } \\
l & \text { liquid } \\
l l & \text { liquid line } \\
v & \text { vapor } \\
v l & \text { vapor line } \\
w & \text { wick } \\
\hline
\end{array}
$$

\section{Introduction}

With the development of high-power integration in electronics, the demand of heat dissipation for spacecraft and large space stations is increasing, and thermal management in the conditions of high heat flux and multi-heat sources distribution is increasingly prominent. Multi-evaporator two-phase loop system exhibits tremendous potential in both theoretical research and ground applications in the multi-heat sources complex thermal conditions. Especially with the concept change in future small spacecraft thermal control system from isolated direct heat dissipation to the centralized thermal management, the development of multi-evaporator two-phase loop system is of great importance and impendency as the first choice of the long-distance highly-efficient heat acquisition/transport/rejection systems, from multiple high-power integrated electronic boxes to space radiators [1].

Currently, there are mainly three types of multi-evaporator two-phase loops: multi-evaporator loop heat pipe (ME-LHP), multi-evaporator capillary pump loop (ME-CPL) and multi-evaporator hybrid loop heat pipe (ME-HLHP), which were derived and developed from LHP, CPL, combined LHP and CPL, respectively. Bugby et al. [2-3] illustrated the architectures, the distinctive and unique characteristics of such two-phase loop options. Among them, ME-LHP has distinct advantages such as high 
system heat transport capability, high pumping, self-starting capability, ability to cool multiple heat sources, heat load sharing among multiple evaporators, flexibility in system design and operation, and has therefore become attractive to the thermal control for spacecraft and high-power electronics applications.

In present, there are two typical ME-LHP systems depending on the layout of evaporator and compensation chamber (CC). One type is multiple evaporators in parallel with a common CC (Fig. 1a), whose operation resembles CPL with the weaknesses of instability during start-up, relatively low capillary pumping and heat transport capability. The other type is individual evaporators in parallel, each having its own CC (Fig. 1b). This type was developed from conventional LHP whose advantages were inherited, but its number of evaporators is limited. ME-LHP can be configured either with one common condenser or with multiple condensers. ME-LHPs with multiple condensers as shown in Fig. 1 is also called ramified LHP [4-5], have been developed in many applications requiring multi-sinks.

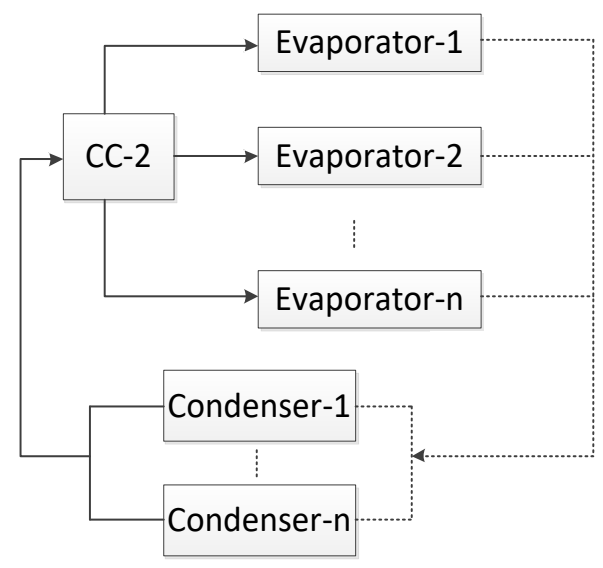

(a) Multi-evaporator sharing common CC

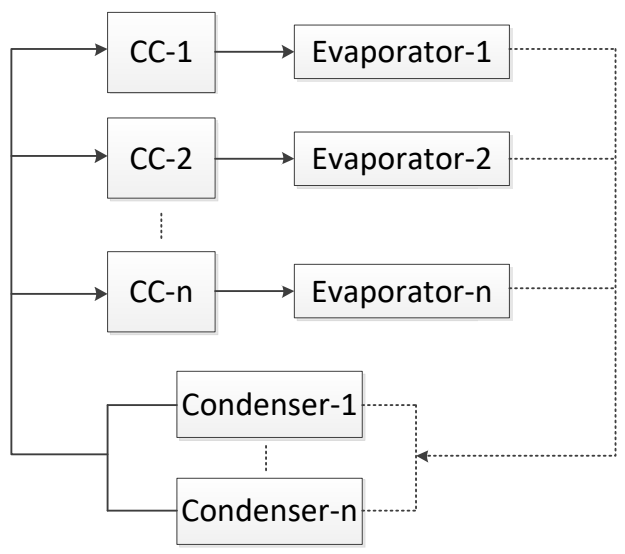

(b) Multi-evaporator each with its own CC

Fig. 1 Two types multiple -evaporator LHP configuration

In the open literature, the most investigated ME-LHP is the LHP with dual evaporators and single/dual condensers (DE-LHP). Therefore, DE-LHP is taken as an example to clarify the configuration and operation modes of ME-LHP. As shown in Fig. 2, DE-LHP consists of two evaporators, two condensers, vapor lines, liquid lines and a working fluid. The evaporators and the condensers are connected in parallel with vapor lines and liquid lines. Each evaporator has a CC and porous wicks. According to the application pattern of heating to evaporators, there are generally two operation modes: parallel mode and heat sharing mode. In parallel mode, heat loads are applied to both evaporators. The vapor generated in both evaporators first converges in the common vapor line, and then separately travels along each vapor line to each condenser where it 
rejects heat to a sink and meanwhile changes back to liquid phase. The liquid again converges in the common liquid line, flows along individual liquid line and enters respective CC to replenish the liquid in the porous wick. In heat sharing mode, heat load is only applied to one evaporator and the other evaporator actually functions as a condenser. Just as Fig. 2b shows, partial vapor generated in evaporator 1 enters into evaporator 2 and raises the temperature of CC2 via the thermodynamic and hydrodynamic links among two CCs and two evaporators. Therefore, as long as the liquid from evaporator 2 has higher temperature than the returning liquid from condensers, the CC2 is in two-phase state and controls the operation temperature.

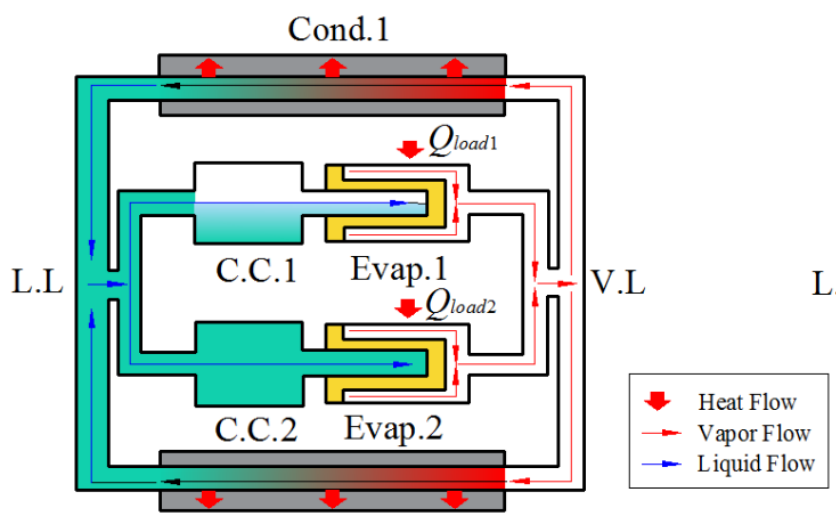

Cond. 2

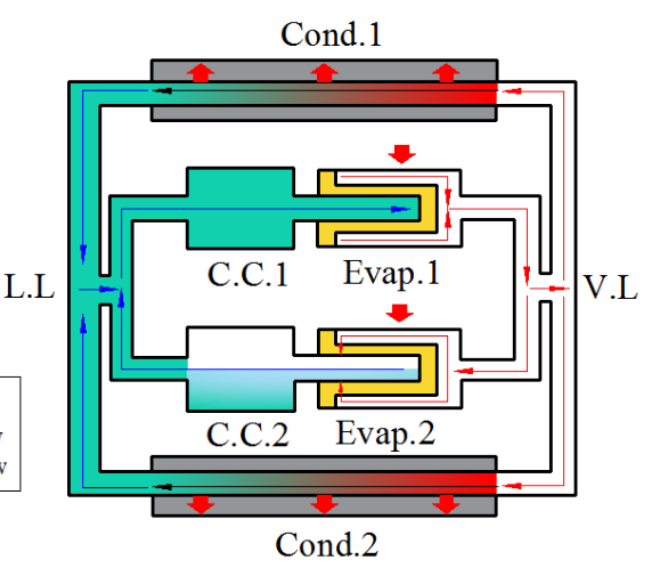

(b) Heat load to one evaporator

(a) Heat load to both evaporators

Fig. 2 Schematic of dual-evaporators/dual-condensers LHP [6]

The performance features of a DE-LHP were summarized by $\mathrm{Ku}$ et al. [7]. The first feature is the fluid distribution of CC under normal operating conditions. Typically, only one CC contained two-phase fluid and the other CC was completely liquid-filled. The second feature is about the control of loop operating temperature. The loop operating temperature can be actively controlled at the desired set-point temperature and normally governed by the $\mathrm{CC}$ with higher temperature. The third feature is that the control of the loop operating temperature could shift from one CC to the other as the operating conditions change. The fourth feature is that two evaporators could share the heat load when only one of the evaporators receives heat load. All the features above also occur in ME-LHP according to Helden et al. [4].

From the above, ME-LHP retains all features of state-of-the-art LHP and offers additional advantages to enhance the functionality, performance, versatility, and reliability of the system. The operational and design feasibility has been verified [2]. However, there are still some research areas that compel immediate attention. For example, if the number of evaporator can increase unlimitedly, what results will be 
induced and what methods can then solve this problem? Another example is that what are the differences in the design theory between ME-LHP and conventional LHP, typically issues are how to select a fluid charge and CC volume. In addition, as known to all, modeling a conventional (single evaporator-CC/single condenser) LHP is already difficult enough, particularly the modeling of transient phenomena. Only a handful of computer codes are available for both steady state and transient simulations of conventional LHPs. For multiple pump/multiple condenser LHP systems, much more effort will be made to develop the analytical model to predict the operational behavior and it is therefore meaningful to review the status of analytical models for ME-LHP. Moreover, ME-LHP has its distinct operational features, such as how the loop operating temperature switches among the multiple CCs, what factors influence the heat sharing, etc.

The current paper will focus on ME-LHP to summarize important research progress in four aspects for the first time: design theory, mathematical models, steady-state operational performance and start-up performance. The key issues of ME-LHP system design include the number limit for evaporators, the sizing of compensation chamber and the calculation of working fluid charge, which will be discussed in section 2 . In section 3, the preliminary analytical models for ME-LHP although will be reviewed, although the refined and well-recognized models have remained to be developed with the insights to the heat transfer and fluid flow mechanisms. The steady operation performances of ME-LHP will be discussed in section 4. Three peculiar issues are reviewed, including the heat load sharing feature, the control rights switching of ME-LHP operation temperature among the multiple CCs and the capillary limit of ME-LHP. Finally, the start-up characteristics of ME-LHP are investigated in section 5 including the effect of required superheat and initial fluid distribution on start-up.

\section{Design theory of ME-LHP}

LHP design is an extremely complicated process mainly involving four procedures [8]. The first step is to identify the thermal performance requirements in the problem statement such as maximum transport capacity, operating temperature range. The second step involves preliminary selection of a working fluid, wick material and case material. The third step involves the use of mathematical models to predict primary heat transfer characteristics such as maximum heat load, pressure losses and operational temperatures for LHP components. Finally, the experimental testing for performance verification of initial designs, the evaluation criteria such as the cost and manufacturing techniques are applied to determine the optimum solution. 
For any design of all LHPs with single evaporator or LHP with multiple evaporators, three key design issues should be taken into account [9]. The first is the ratio between LHP components volume. The second is the compensation chamber volume. The third is the mass of charged working fluid.

\subsection{Constrain of the number of evaporators}

The number of evaporators and sizing of the CC volume are two limiting problems in ME-LHP design and practical application. The requirement that each CC volume had to be large enough to contain liquid at all times even when the other CCs and the rest of the loop were liquid-filled made the reservoirs intolerably large, limiting the number of evaporators to two for practical purpose [1]. Goncharov et al. [9] pointed out that the number of evaporators is limited by a certain ratio between LHP components volume and the charged working fluid mass. Yun et al. [10] provided detailed analysis of how the ME-LHP compensation chamber volume varies with the number of the evaporators (N) for a typical LHP system (ALPHA LHP). On the basis of their work, Bugby et al. [2] made a simplified analysis for generalized LHP system and pointed out that CC volume of ME-LHP increases with $\mathrm{N}$, eventually becoming infinite for $\mathrm{N}$ greater than around 4 .

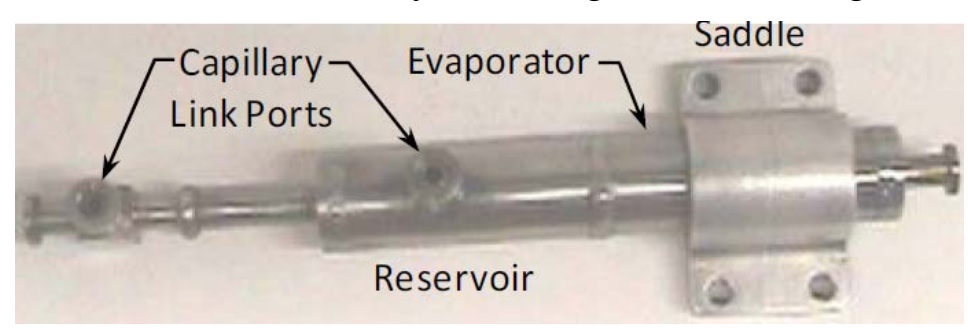

Fig. 3 ME-LHP Evaporator/Reservoir with capillary link ports [1]

From existing literatures, it is indeed that the majorities of all developed and tested ME-LHPs are two-evaporator LHPs. However, a novel concept of ME-LHP was recently proposed by Hoang and $\mathrm{Ku}$ [1] in which the CCs were "capillary-linked" together so that a liquid-starved CC can still prime its primary wick with no limit in the numbers of evaporators of ME-LHP. A four-evaporator LHP was fabricated and tested. The test results showed that the ME-LHP with four evaporators worked well in typical LHP operations. The intra-capillary links between multiple CCs were realized by two more ports configuration on the CC design as shown in Fig. 3. One port only allowed liquid to flow in or out of CC, the other port had access only to the vapor space in CC. Each port forms manifold together with small-diameter tubing to form intra-capillary links. The capillary links enabled an evaporator with an empty reservoir to draw liquid from any other reservoir to keep its own primary wick primed. Hence, ME-LHP reservoir sizing was not limited by the evaporator number. In the four-evaporator LHP 
with this new concept, each CC volume was $9.6 \mathrm{ml}$, which was less than one-fiftieth of CC volume (typically $500 \mathrm{ml}$ to operate in the $-20^{\circ} \mathrm{C}$ to $80^{\circ} \mathrm{C}$ range) for a conventional four-evaporator LHP.

Even though the majority of existing efforts have been focused on DE-LHP which performed well in laboratory, the required CC volume is much larger and this hinders its further application for space. To keep the total CC volume of ME-LHP not larger than that of the single evaporator LHP counterpart is very likely the future research direction of ME-LHP. The new concept of capillary-linked-CCs provided by Hoang and Ku [1] is a good attempt whose innovative idea exists that the intra-liquid-replenish among multiple evaporators and CCs makes each evaporator no longer solely rely on its connected CC, therefore breaking the stipulation of the number of evaporators for ME-LHP.

\subsection{Calculation of Compensation Chamber Volume}

For conventional single-evaporator LHP, two design approaches can be used to effectively select a fluid charge and CC volume that would yield optimum performance characteristics [8]. One approach was documented by $\mathrm{Ku}$ [11] and there was no theoretical upper limit for CC volume in the Ku's method. The CC volume must be able to accommodate at least the swing volume between the hot and cold case of loop operation and should be optimized with the fluid inventory to accommodate space and weight constraints. The second approach, proposed by TAIS Ltd [12], is more conservative assuming there is always sufficient liquid in the LHP for start-up. That is, LHP always starts up with some heat load even in the most unfavorable conditions and orientations.

Generally there are two design conditions to consider when developing an LHP: the worst cold case and the worst hot case. In the worst cold case, no heat is applied to evaporator while the rest of the loop (condenser, liquid line and vapor line) are exposed to the coldest environmental conditions. In the worst hot case, maximum power is applied to evaporator while the rest of the loop is exposed to the hottest environmental conditions. The CC sizing design should satisfy three aspects: firstly to guarantee enough liquid to evaporator for start-up during the worst cold case. Secondly, to prevent condenser blockage during worst hot case so that minimize the volume of condenser. Thirdly, the CC should be sized to compensate for the thermal expansion of the working fluid between the worst cold case and the worst hot case. 
For the design of LHP with multiple evaporators/condensers, the two worst cases are similar to those for LHP with a single evaporator [9]. Goncharov et al. [9,13] proposed Eqs. (1-2) to check the CC volume. It is assumed that multiple evaporators with its own CC and multiple CCs have the same volume. The scenario of liquid distribution for ME-LHP ( $\mathrm{N}=3)$ was shown in Fig. 4.

$$
\begin{aligned}
& V_{c c_{i}} \geq \frac{\left(V_{v l}+V_{\text {cond }}\right) \cdot\left(\rho_{l, c}-\rho_{v, h}\right)+\left(\sum_{i=1}^{N} V_{e v_{i}}+V_{l l}\right) \cdot\left(\rho_{l, c}-\rho_{l, h}\right)}{n \cdot \rho_{l, h}-(N-1) \cdot \rho_{l, c}} \\
& V_{e v_{i}}=n \cdot\left(V_{w} \cdot \varepsilon+V_{g r}+V_{\text {space }}\right)
\end{aligned}
$$

where $V_{v l}$ is the volume of vapor line; $V_{\text {cond }}$ is the volume of condenser; $V_{w}$ is the volume of wick; $V_{g r}$ is the volume of vapor groove; $V_{l l}$ is the volume of liquid line; $\rho_{l, c}$ is the density of liquid in the worst cold case; $\rho_{l, h}$ is the density of liquid in the worst hot case; $\rho_{v, h}$ is the density of vapor in the worst hot case; $N$ is evaporator numbers; $\varepsilon$ is the wick porosity; $V_{\text {space }}$ is the space volume at the evaporator which depends on the specific design of evaporator.

To the best knowledge of the authors, Eqs. (1-2) are the only validated formula for ME-LHP design in open literature. To prove the design theory above, several ME-LHP samples were manufactured and tested. LHPs with two and three evaporators operate successfully and no deviations were observed during testing [9]. One point should be stressed is that the calculation formula in Eqs.(1-2) was derived without taking into account the temperature change along the length of the loop and the presence of the liquid film in condenser at maximum applied heat load. CC volume and mass of liquid-charge can be reduced by taking into account these corrections.

\subsection{Calculation of working fluid charge}

Fluid charge is an important LHP design parameter mainly for two reasons. Firstly, fluid charge has significant impact on the initial distribution of liquid-vapor phase in LHP evaporator core. Whether or not the evaporator core exists vapor bubbles will greatly influence the radial heat leak between evaporators and their connecting CC, and consequently affect the LHP operation. The sensitivity experiment results of LHP performance with respect to fluid charge have shown that both low and high fluid charge will result in an increase of the loop operating temperature [8]. If the fluid charge is too low, wick dry-out is prone to occur with the increase of input power and induces to the increase of loop operating temperature. If the fluid charge is too high, there may 
not be sufficient room in the CC to accommodate the excess liquid. The liquid stagnates and increases in temperature due to parasitic heating. This in turn increases the loop operating temperature. Secondly, LHP start-up is strongly influenced by the fluid charge, and particularly by the fluid distribution in the LHP before starting [14]. For example, smaller fluid charges were found to require less time for initiation of fluid flow since less liquid was available to collect in the vapor grooves while higher fluid charges will prolong the start-up time due to excess liquid collection in the vapor grooves which increase the required superheat.

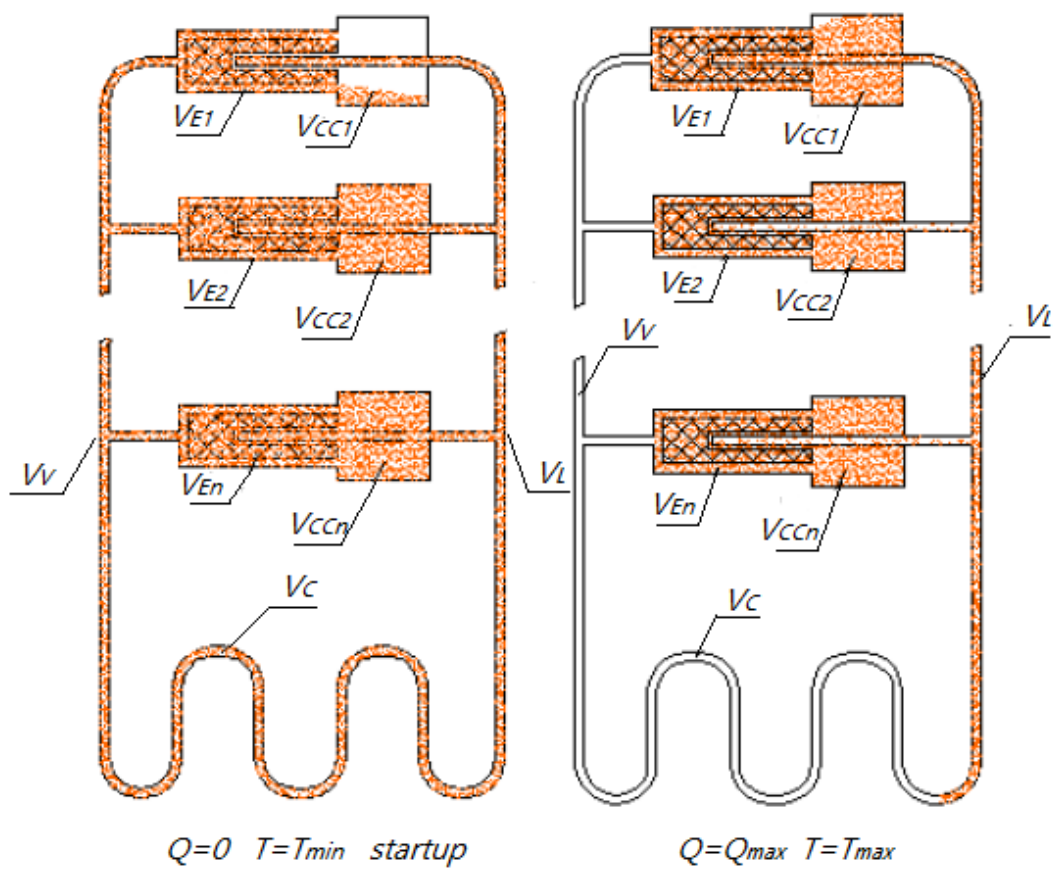

Fig. 4 Liquid distribution of ME-LHP in cold critical case (left) and at maximum heat transfer (right) [13]

The CC volume and mass of fluid to be charged are often obtained concurrently. The principles of inventory calculation for ME-LHP are similar to the conventional LHP. As shown in Fig. 4, the worst cold case, ME-LHP is charged so that some liquid is left in one CC while other CCs and the rest of the loop are completely flooded. The working fluid amount is of the minimum value in the worst cold case because further decrease of the liquid amount in the CC with some liquid can lead to deprime the evaporator connected to this CC. In the worst hot case, when the maximum heat load is applied to the evaporator and the heat sink temperature is at its maximum, some vapor space is available in one CC while other CCs and the liquid line are flooded meanwhile the condenser is fully utilized (i.e. vapor line and condenser is filled with vapor). That is, CC volume should be sufficient [9] to contain the following: 1) Liquid pushed out from vapor line and condenser; 2) Increased volume of liquid due to heating from the minimum temperature to the maximum temperature; 3) Additional liquid pushed out 
due to vapor/liquid interface displacement inside the wick at the maximum heat load; 4) Non-condensable gas. In addition, for both worst cases, some extra amount of working fluid charge should also be considered to compensate LHP calculation, manufacturing and charging tolerance.

Goncharov et al. [13] proposed Eqs. (3-4) to calculate the fluid inventory of ME-LHP in the worst cold case and the worst hot case, respectively:

$$
\begin{aligned}
& M_{c}=\rho_{l, c}\left(V_{\text {loop }}+(N-1) V_{c c}+\beta V_{c c}\right)+\rho_{v, c}\left[(1-\beta) V_{c c}\right] \\
& M_{h}=\rho_{l, h}\left(V_{l l}+\varepsilon V_{w}+(N-1) V_{c c}+(1-\alpha) V_{c c}\right)+\rho_{v, h}\left[\alpha V_{c c}+V_{g r}+V_{v l}+V_{c o n d}\right]
\end{aligned}
$$

where $V_{\text {loop }}$ is loop total volume excluding the CC; $\beta$ is the fraction of compensation chamber volume occupied by the liquid at cold case; $\alpha$ is the void fraction of the compensation chamber in hot case. $\mathrm{Ku}$ [15-16] states that $\beta$ and $\alpha$ values are selected at the designer's discretion and a careful selection of these two values will yield the optimal CC volume and fluid inventory. Okutani et al. [17] and Matsuda et al. [18] have used Eqs. (3-4) to determine the fluid inventory for two-evaporator two-condenser LHP respectively using PTFE wick and porous stainless steel wick. Both experimental results demonstrated the stable operation of ME-LHP in various conditions. Eqs. (3-4) have been widely accepted to calculate fluid charge in ME-LHP design.

\section{Mathematical Modeling of ME-LHP}

Up to 2004, over 100 conventional LHPs have been utilized for spacecraft thermal control systems. The multiple evaporator/condenser LHPs are the next logical step in the LHP utilization [19]. Although LHP with multiple evaporators/multiple condensers have shown to function very well in ground testing, some complex issues still wait to be solved due to the complicated behavior related to the interaction between the multiple evaporators and condensers. To promote ME-LHPs application in the spacecraft thermal control systems, more accurate models are required to predict their thermal performance. The calculation procedure for LHP can be divided into two main parts: one is the pressure drop calculation and the other is the heat transfer calculation [20]. Various calculation models have been developed for modeling a single evaporator LHP. The software for LHP modeling includes Easy 2000 with the embedded Buz and Goncharov's model [21], the SINDA/Fluint with the Cullimore and Baumman model [22]. The most investigated models for conventional LHP with cylindrical evaporators mainly include: 1) 1D steady-state analytical model developed by Maydanik [23]; 2) 1D steady-state numerical model for LHP system by Kaya and Hoang [24]; 3) 2D steady-state LHP evaporator model developed by Kaya and Goldak [25], which together 
with the Demidov model [26] and the Figus pore network model [27], lay particular emphasis on the heat and mass transfer with phase change in porous wicks. The comprehensive literature review has elucidated by Siedel et al. [28] focused on the existing steady-state models of LHPs with single evaporator. 4) 1D transient models. The transient model by Launay et al. [29] characterized LHP oscillations. The transient model by Chernysheva and Maydanik [30] focused on the cylindrical evaporator only considering radial heat transfer. Ref. [31-33] were for system-level transient operation. Both models respectively developed by Kaya et al. [31] and Nishikawara et al. [32] simulate the LHP transient behavior including the start-up phase.

For ME-LHP modeling, Maydanik [34] brought up a hydrodynamic model to calculate the maximum capacity of an LHP with multiple evaporators and condensers at different heat-load distribution between the evaporators and different device orientations. ME-LHP system was divided into different hydrodynamic homogeneous sections. The sum of pressure losses in all sections was not larger than the total capillary heads in both evaporators. The pressure loss in each section was a function of the heat load transferred in the section and can be expressed as the function of thermal resistance. Therefore the model can be described in the thermal network approach. Matsuda et al. [18] proposed a new evaporator-CC model to reflect the vapor-liquid distribution and further evaluated the amount of heat leak of ME-LHP respectively under $1 \mathrm{~g}$ and $\mu \mathrm{g}$ environments. The new evaporator-CC model is much detailed in heat transfer mechanism compared to the conventional counterpart. For example, the heat transfer between the wick and evaporator core was modeled from two paths: the heat transfer from wick to the vapor of core and to the liquid of the core, instead of simulation as a whole. Chang and Nagano [35] developed a steady model for LHP with dual evaporators (each with a CC) and dual condensers using the node-path thermal network. The thermal network of each evaporator/CC pump composed of ten thermal nodes and connected thermal path, which showed very little difference from the convention LHP model. The difficulty is to predict the temperature at the confluence point (that is, the inlet points of the common vapor line and common liquid line, as shown in Fig. 2) in the dual evaporator LHP model. Assuming all the fluid is vapor at the common vapor line inlet, ideal gas enthalpy equation is used to evaluate the temperature of the confluence point. The vapor fraction can be calculated according to the pressure of the confluence point. The similar principle is used to calculate the temperature and vapor faction of inlet of common liquid line. The specific equations can be found in Ref. [35].

In 1993, Hoang and Ku [33] developed an LHP transient model. The model governing 
equations show that the fluid flow of LHP behaves like a mass-spring-damper dynamical system. They further extend this model to simulate ME-LHP assuming governing equations for ME-LHP are similar to those of single evaporator/condenser LHP. The derivation of the governing equations for LHP with multiple evaporators and condensers is broken into two independent parts. One is for the heat rejection and fluid flow distribution among the parallel condensers. The other set of governing equations is for the energy balance in the parallel evaporators-CC assemblies. All the governing equations are built based on the conservation laws of mass, momentum and energy using the Lagrangian method and solved using Runge-Kutta numerical scheme. The analytical model employed a nodal approach for the finite difference solution scheme. This model is capable of simulating the ME-LHP performance within the capillary limit and the predictions will be inaccurate once the capillary limit has been exceeded. The detailed solving code of steady state was verified in Ref. [19] and the detailed solving code of transient was described in Ref. [36]. This ME-LHP model has been verified with excellent agreement between the model predictions and the experimental results for the ME-LHP breadboard and proto-flight unit in the laboratory and thermal vacuum environments [15, 39-40]. To the author's knowledge, this is the most specific transient analytical model for ME-LHP in the open literature.

As shown above, there are very few analytical models for LHPs with multiple evaporators and condensers in either steady-state or transient modes. The reasons are firstly, the heat transfer mechanism of ME-LHP are still not clear, such as the complex nature of thermal interactions between the multiple evaporators/condensers, also between the LHP itself and the operational environment. Secondly, the methodology of solving the equations is too complicated and new computer codes have to be developed from scratch for ME-LHP. The future development direction in ME-LHP modeling could be, to develop the multiple evaporators-CC-level models, and then take them as the sub-models to integrate to the existing LHP system-level models. With the trends for small and micro-satellites development, the research of miniature ME-LHP with evaporator diameter down to $10 \mathrm{~mm}$ will present greater challenges in ME-LHP modeling.

\section{ME-LHP steady operational performance}

The theoretical and experimental research on ME-LHP originated in 1988 and 1992, respectively [13]. These were mainly involved in the feasibility of ME-LHP [2, 37-38], the system design [1-2, 8-10, 14, 17], the mathematical modeling [6, 35-36], the steady operation and start-up performance. The feasibility of ME-LHP was firstly 
demonstrated by Bienert.et al. [37] in 1997, which showed the performance of dual-evaporator LHP is similar to the performance of single-evaporator LHP in terms of reliability, self-starting capability, heat transport capacity and thermal conductance.

In the last 20 years, extensive operating characteristics tests of ME-LHP have been conducted in several research institutions. In 1997, an LHP with two identical evaporators and a condenser was tested for the first logical step in Dynatherm Corporation/DTX, Wright Laboratory of America and Institute of Thermal Physics/TAIS Ltd. of Russia. These tests clearly demonstrated the feasibility and reliable operating characteristics of a dual evaporator LHP. In 1998, "Push-Pull” LHP with two identical evaporators which can realize the bidirectional heat transfer and “Zmey Gorynych” LHP with three parallel evaporators and two parallel condensers (as shown in Fig. 5) were developed and tested successfully by TAIS Ltd. [9], proving the preliminary design theory developed for multi-evaporator LHP. During 2001-2012, under the sponsorship of NASA, the Dynatherm Corporation/ NASA Goddard Space Flight Center (NASA/GSFC) developed several LHP with two evaporators and two condensers for potential Mars Rover applications [11, 15-16, 36, 39-42]. The miniature ME-LHPs for future small systems applications requiring low mass, low power and high compactness were also developed and demonstrated excellent performance in proof-of-concept program [15-16] and proto-flight unit thermal vacuum testing [39]. During the recent ten years, TTH Research Inc. [1], NASA/GSFC [15-16, 39-40] and Nagoya University [6, 17-18, 44] in Japan have been very active in ME-LHP research. All the relevant ME-LHPs mentioned above in the last 20 years are summarized in Table 1, including the configurations of multi-evaporators and multi-condensers, the material of ME-LHP components, the working fluid, the wick material and the main test results in different test conditions.
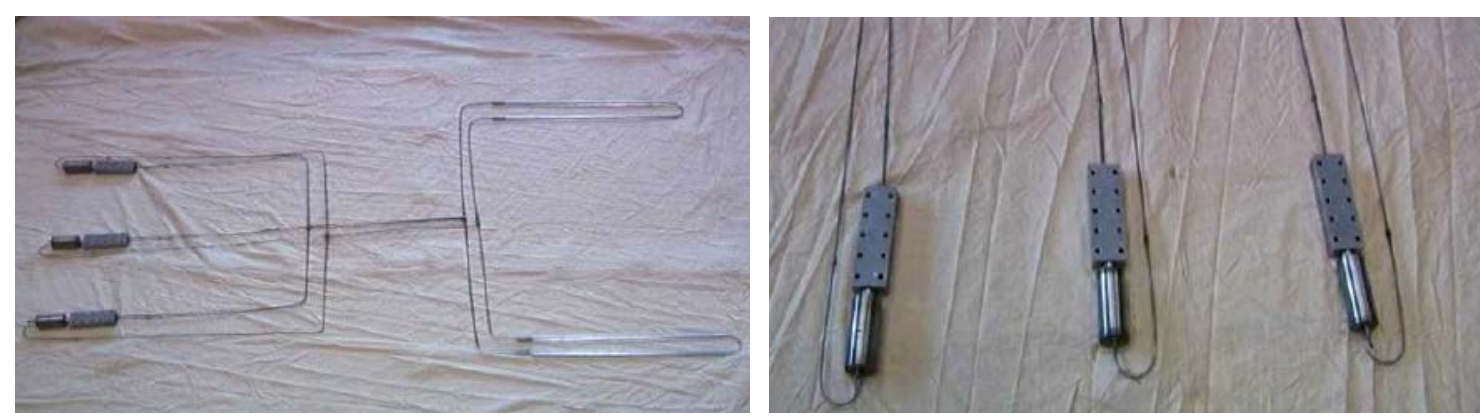

Fig. 5 Photos of “Zmey Gorynych” LHP Evaporators [9] 
Table 1 Summary of experimental investigation on ME-LHP

\begin{tabular}{|c|c|c|c|c|c|c|}
\hline Year & $\begin{array}{l}\text { Investigat } \\
\text { or }\end{array}$ & $\begin{array}{l}\text { Number } \\
\text { of } E^{*} / C^{*}\end{array}$ & $\begin{array}{l}\text { Material } \\
\text { /Working fluid }\end{array}$ & Main size & Test conditions & Comments \\
\hline 1997 & $\begin{array}{l}\text { Bienert.et } \\
\text { al. [37] }\end{array}$ & $2 \mathrm{E}-1 \mathrm{C}$ & $\begin{array}{l}\text { SS for E/titanium } \\
\text { wick/water }\end{array}$ & $\begin{array}{l}\text { E: ID/length:22/100mm } \\
\text { CC: length:58mm } \\
\text { VL: ID/length:3/1030+100mm } \\
\text { LL: ID/length:3/1000+200mm } \\
\text { C: ID/length:22/180mm }\end{array}$ & $\begin{array}{l}\text { Heat load applied mode, } \\
\text { power cycles, sink cycles, } \\
\text { gravity effect }\end{array}$ & $\begin{array}{l}\text { It can be started by applying power to one or both evaporators; } \\
\text { response to power and sink transients is quite acceptable; } \\
\text { operated successfully with evaporators powered uniformly, } \\
\text { non-uniformly, and no power, with different evaporator } \\
\text { elevations relative to the condenser. }\end{array}$ \\
\hline 2000 & $\begin{array}{l}\text { Goncharo } \\
\text { v et al. [9] }\end{array}$ & $3 E-1 C$ & $\begin{array}{l}\text { SS for E,VL,LL } \\
\text { aluminum } \\
\text { condenser, nickel } \\
\text { wick }\end{array}$ & $\begin{array}{l}\text { E: OD/length:17.4/155mm } \\
\text { VL: ID: } 4 \mathrm{~mm} \\
\text { LL: ID:3mm } \\
\text { C: ID: } 4 \mathrm{~mm}\end{array}$ & $\begin{array}{l}\text { Gravity effect (tilt angels in } \\
\text { the range of } \pm 75^{\circ} \text { ), heat load }\end{array}$ & $\begin{array}{l}\text { No deviation of LHP operation characteristics were observed } \\
\text { when LHP testing. It allows asserting that theory developed for } \\
\text { multi-evaporator LHP designing and calculation provides the } \\
\text { reliable data. }\end{array}$ \\
\hline 2001 & $\begin{array}{l}\mathrm{Ku}, . \text {.Birur } \\
{[42]}\end{array}$ & $2 \mathrm{E}-2 \mathrm{C}$ & $\begin{array}{l}\text { SS for E,VL,LL,C, } \\
\text { titanium/ nickel } \\
\text { wick/ammonia }\end{array}$ & $\begin{array}{l}\text { E: OD/length:12.7/76.2mm } \\
\text { VL:OD/length:1.59/1168mm } \\
\text { LL: OD/length:1.59/1168mm } \\
\text { C: OD/length:1.59/508mm }\end{array}$ & $\begin{array}{l}\text { Start-up, power cycle, sink / } \\
\text { reservoir temperature cycle, } \\
\text { capillary limit }\end{array}$ & $\begin{array}{l}\text { Back flow occurred when CC is preheating. Low power } \\
\text { start-up is still problematic as with single evaporator LHP. The } \\
\text { test loop has demonstrated very robust operation even during } \\
\text { fast transients. }\end{array}$ \\
\hline 2001 & $\begin{array}{l}\mathrm{Ku}, . \text {.Birur } \\
{[11]}\end{array}$ & $2 \mathrm{E}-2 \mathrm{C}$ & $\begin{array}{l}\text { aluminum E, SS for } \\
\text { VL,LL,C, titanium/ } \\
\text { nickel } \\
\text { wick/ammonia }\end{array}$ & $\begin{array}{l}\text { E: OD/length:15.8/76.2mm } \\
\text { CC: OD/length:14.8 /81.8mm } \\
\text { VL/LL: OD/length:2.2/1168mm } \\
\text { C: OD/length:2.2 /177.8mm }\end{array}$ & $\begin{array}{l}\text { Stability of loop operating } \\
\text { temperature }\end{array}$ & $\begin{array}{l}\text { Operating temperature is a function of heat load, sink /ambient } \\
\text { temperature, heat load distribution between two evaporators. } \\
\text { As the test condition changes, control of the loop operating } \\
\text { temperature often shifted from one CC to another. }\end{array}$ \\
\hline 2003 & $\begin{array}{l}\text { Maydanik } \\
\text { et al. [34] }\end{array}$ & $2 \mathrm{E}-2 \mathrm{C}$ & $\begin{array}{l}\text { SS for E, CC, } \\
\text { VL,LL,C, Nickel } \\
\text { wick/ammonia }\end{array}$ & $\begin{array}{l}\text { E/CC: OD/length:24/150mm } \\
\text { LL/VL: OD:4/6mm } \\
\text { C: OD/length:24/200mm } \\
\text { ME-LHP total length:1000mm }\end{array}$ & $\begin{array}{l}\text { Various device orientations, } \\
\text { heat load distributions } \\
\text { between evaporators, different } \\
\text { condenser cooling }\end{array}$ & $\begin{array}{l}\text { The maximum capacity varies from } 1100 \text { to } 1400 \mathrm{~W} \text { for all } \\
\text { device orientations and decreased abruptly if only one of the } \\
\text { condensers was actively cooler. }\end{array}$ \\
\hline 2005 & $\begin{array}{l}\text { Ku et al. } \\
{[36]}\end{array}$ & $2 \mathrm{E}-2 \mathrm{C}$ & $\begin{array}{l}\text { aluminum for E, } \\
\text { titanium/ nickel } \\
\text { wick/ammonia }\end{array}$ & $\begin{array}{l}\text { E: OD/length:15.8 /76.2mm } \\
\text { CC: OD/length:14.8 /81.8mm } \\
\text { VL: OD/length:2.2/1168mm } \\
\text { LL: OD/length:1.6/1168mm } \\
\text { C: OD/length:2.2 /177.8mm }\end{array}$ & $\begin{array}{l}\text { Even/uneven heat load, } \\
\text { power increment, different } \\
\text { sink temperature }\end{array}$ & $\begin{array}{l}\text { Titanium wick is first partial dry-out and the CC with titanium } \\
\text { wick controls the loop saturation temperature with even heat } \\
\text { load. The evaporator with less heat input control the loop } \\
\text { saturation temperature with uneven heat load. }\end{array}$ \\
\hline 2006 & $\mathrm{Ku}$ [43] & $2 \mathrm{E}-2 \mathrm{C}$ & $\begin{array}{l}\text { aluminum for E, } \\
\text { SS for } \\
\text { VL,LL,C,CC; } \\
\text { titanium/ nickel } \\
\text { wick/ammonia }\end{array}$ & $\begin{array}{l}\text { E: OD/length: } 13 / 76.2 \mathrm{~mm} \\
\text { CC: OD/length: } 18 / 61 \mathrm{~mm} \\
\text { VL: OD/length:2.38/1200mm } \\
\text { LL: OD/length:1.59/1200mm } \\
\text { C:OD/length:2.38/760mm/each }\end{array}$ & heat load sharing & $\begin{array}{l}\text { The heat shared by the evaporator was mainly affected by heat } \\
\text { load applied to the other evaporator and the temperature of the } \\
\text { sink surrounding the evaporator sharing the heat, much less } \\
\text { affected by the condenser sink temperatures. }\end{array}$ \\
\hline 2007 & $\begin{array}{l}\text { H.Nagano. } \\
\text { et al.[6] }\end{array}$ & $2 \mathrm{E}-2 \mathrm{C}$ & $\begin{array}{l}\text { aluminum } 6061 \text { for } \\
\text { E,C; stainless steel } \\
\text { for } \\
\text { CC,VL,LL,/titanium } \\
\text { wick/ammonia }\end{array}$ & $\begin{array}{l}\text { E: OD/length:9.65 /52mm } \\
\text { CC: OD/length:22.2 /72.4mm } \\
\text { VL: OD:2.38mm } \\
\text { LL: OD:1.59mm } \\
\text { C: OD/length:2.38/2540mm }\end{array}$ & $\begin{array}{l}\text { Heat load applied mode, } \\
\text { w/\&w/o active control of CC } \\
\text { temperature, gravity effect }\end{array}$ & $\begin{array}{l}\text { LHP can operate at a new steady state when capillary limit was } \\
\text { exceeded. TEC is effective in controlling the CC temperature } \\
\text { Under vertical configuration, the operating temperature is } \\
\text { higher and the transport capability is lower than those under } \\
\text { horizontal configuration. }\end{array}$ \\
\hline
\end{tabular}




\begin{tabular}{|c|c|c|c|c|}
\hline 2011 & $\begin{array}{l}\text { Ku et al. } \\
\text { [39] }\end{array}$ & $\begin{array}{l}\text { 2E-2C } \\
\text { miniature } \\
\text { ME-LHP }\end{array}$ & $\begin{array}{l}\text { aluminum for E; } \\
\text { SS304L for } \\
\text { VL,LL,C,CC; } \\
\text { primary/secondary } \\
\text { wick: } \\
\text { titanium/SS304L; } \\
\text { ammonia }\end{array}$ & $\begin{array}{l}\text { E: OD/length:9/52mm } \\
\text { CC: OD/length:22.5 /76.7mm } \\
\text { VL: OD/length:2.38/1580mm } \\
\text { LL: OD/length:1.59/1102mm } \\
\text { C: OD/length:2.38 /1676mm }\end{array}$ \\
\hline 2012 & $\begin{array}{l}\mathrm{Ku} \quad \text { et } \\
\text { al.[7], } \\
{[15-16]}\end{array}$ & $\begin{array}{l}\text { 2E-2C } \\
\text { miniature } \\
\text { ME-LHP }\end{array}$ & $\begin{array}{l}\text { aluminum for E; SS } \\
\text { for VL,LL,C,CC; } \\
\text { primary/secondary } \\
\text { wick:titanium/SS30 } \\
\text { 4L; ammonia }\end{array}$ & $\begin{array}{l}\text { E: OD/length:9/52mm } \\
\text { CC: OD/length:22.2 /72.4mm } \\
\text { VL: OD/length:2.38/914mm } \\
\text { LL: OD/length:1.59/914mm } \\
\text { C: OD/length:2.38 /2540mm }\end{array}$ \\
\hline 2014 & $\begin{array}{l}\text { Okutani. } \\
\text { et al.[17] } \\
\text { Chang et } \\
\text { al. [35] }\end{array}$ & $-2 C$ & $\begin{array}{l}\text { stainless steel/PTFE } \\
\text { wick/ pure acetone }\end{array}$ & $\begin{array}{l}\text { E: ID/OD/length:9.3/12/70mm } \\
\text { CC: ID/OD/length:34/36/45mm } \\
\text { VL/LL/C: ID: } 1.75 \mathrm{~mm} \\
\text { VL/LL/C:length:770/800/500mn }\end{array}$ \\
\hline 2015 & $\begin{array}{l}\text { Hoang et } \\
\text { al. [1] }\end{array}$ & $4 \mathrm{E}-1 \mathrm{C}$ & $\begin{array}{l}\text { SS for E,CC,LL,VL,C; } \\
\text { primary/secondary } \\
\text { wick: sintered SS /SS } \\
\text { wiremesh; ammonia }\end{array}$ & $\begin{array}{l}\text { E: OD/length:15.24/31.75mm } \\
\text { CC: OD/length:15.24 /76.2mm } \\
\text { VL/LL:OD/length:2.38/269mm } \\
\text { C: OD/length:2.38/1387.6mm }\end{array}$ \\
\hline 2015 & $\begin{array}{l}\text { Matsuda et } \\
\text { al. [18] }\end{array}$ & $2 \mathrm{E}-1 \mathrm{C}$ & $\begin{array}{l}\text { SUS304 for } \\
\text { E,C,VL,LL, wick, } \\
\text { PFA for C, distilled } \\
\text { water }\end{array}$ & $\begin{array}{l}\text { E: OD/length:21/85mm } \\
\text { CC: OD/length:44/75mm } \\
\text { VL: ID/length:4.6/350mm } \\
\text { LL: ID/length:1.8/500mm } \\
\text { C: ID/length:1.8/1500 mm }\end{array}$ \\
\hline 2016 & $\begin{array}{l}\text { Chang et } \\
\text { al. [44] }\end{array}$ & $2 \mathrm{E}-2 \mathrm{C}$ & $\begin{array}{l}\text { sintered SS wick; } \\
\text { ammonia }\end{array}$ & $\begin{array}{l}\text { E: ID/length:10/59mm } \\
\text { CC: ID/length:37/55mm } \\
\text { VL: ID/length:1.75/1960mm } \\
\text { LL: ID/length:1.75/2455mm } \\
\text { C: ID/length:1.75/3000 mm }\end{array}$ \\
\hline
\end{tabular}

Thermal vacuum test: start-up, power cycle, sink temperature cycle, high power and low power operation, heat load sharing, operating temperature control

75 perating

start-up tests with high /low power, CC active control tests, power cycling tests, heat load sharing tests

power cycle, heat load switching, sink temperature cycle

Start-up and operate tests, It can operate in any combination of power inputs; no limit on heat sharing tests, the number of evaporators due to the design of capillary links functionality tests of capillary among CCs; the overall thermal conductance of the ME-LHP links among parallel was reduced in a heat-load sharing mode.

reservoirs

Visualization of the wick core, the vapor-liquid

distribution in evaporator and

CC under $1 \mathrm{~g}$ and $\mu \mathrm{g}$

Under 1g, top-vapor and low-liquid distribution occurs in $\mathrm{E}$ core and CC for both even and uneven heat load modes. Under $\mu \mathrm{g}$, vapor was present around E core and CC at even heat load, while bubbles initially formed on the internal wall of the core at uneven heat load.

Thermal vacuum test, heat ME-LHP can transport 240W at even heat load case and 200W load applied mode for only one E was heated. Each E can start up at $5 \mathrm{~W}$ with CC preheating.

*E: evaporator; C: condenser; VL: vapor line; LL: liquid line; CC: compensation chamber; SS: stainless steel 


\subsection{Operation Temperature Control}

ME-LHPs not only have all the characteristics of conventional one-evaporator LHPs, but also possess their own peculiarities. The most prominent one is the control rights switching of ME-LHP operation temperature among multiple CCs. Many tests concerning the switching rules were carried out under the conditions of with/without active control on CC temperature [6, 11, 15-16, 41]. Another peculiarity is the heat load sharing feature which are extensively observed in experimental works $[1,10,17$, 39, 43]. In addition, the capillary limit of ME-LHP has displayed much difference from the conventional LHP which were discussed in literatures [2, 6, 15-17, 36-37].

Table 2 Heater Power Matrix

\begin{tabular}{llllllllllll}
\hline \multicolumn{1}{l}{\begin{tabular}{l} 
Operation with individual \\
evaporator heat loads (W) \\
$\begin{array}{l}\text { Case 1: individual } \\
\text { evaporator powered start-up }\end{array}$ \\
\hline E1
\end{tabular} E2 } & E3 & E4 & E1 & E2 & E3 & E4 & E1 & E2 & E3 & E4 \\
5 & 0 & 0 & 0 & 10 & 10 & 10 & 10 & 50 & 0 & 0 & 0 \\
10 & 0 & 0 & 0 & 15 & 10 & 10 & 5 & 40 & 5 & 5 & 0 \\
20 & 0 & 0 & 0 & 20 & 10 & 10 & 0 & 20 & 10 & 10 & 10 \\
30 & 0 & 0 & 0 & 25 & 10 & 5 & 0 & 5 & 15 & 15 & 15 \\
40 & 0 & 0 & 0 & 30 & 10 & 0 & 0 & 0 & 10 & 10 & 30 \\
50 & 0 & 0 & 0 & 35 & 5 & 0 & 0 & 0 & 5 & 5 & 40 \\
40 & 0 & 0 & 0 & 40 & 0 & 0 & 0 & 0 & 0 & 0 & 40 \\
30 & 0 & 0 & 0 & 50 & 0 & 0 & 0 & 0 & 0 & 50 & 0 \\
20 & 0 & 0 & 0 & 40 & 10 & 0 & 0 & 0 & 50 & 0 & 0 \\
10 & 0 & 0 & 0 & 30 & 10 & 10 & 0 & 50 & 0 & 0 & 0 \\
5 & 0 & 0 & 0 & 20 & 10 & 10 & 10 & 20 & 10 & 10 & 10 \\
$/$ & $/$ & $/$ & $/$ & $/$ & $/$ & $/$ & $/$ & 10 & 20 & 10 & 10 \\
$/$ & $/$ & $/$ & $/$ & $/$ & $/$ & $/$ & $/$ & 10 & 10 & 20 & 10 \\
\hline
\end{tabular}

In an LHP with multiple evaporators and multiple condensers, the operating temperature becomes much more complex. Each CC is still subjected to the energy balance and is therefore affected not only by those factors in single-evaporator LHP, such as applied heat load, sink temperature, ambient temperature, but also by the heat load distribution among evaporators, and heat dissipating capability of each condenser. Thus, multiple CCs could hardly reach the same equilibrium temperatures and control of operating temperature can shift from one CC to the other as the heat load distribution changes. Moreover, more temperature hysteresis will exhibit compared to conventional LHP [42]. For active control of operating temperature for ME-LHP, the set point temperature must be set high enough to encompass all temperature hysteresis. 
The results for most tested two-evaporators LHP showed that regardless of one or two CCs used to controlled to the set point temperature, only one CC could contain the two-phase fluid, the other could be at a subcooled state or a superheated state, even when both CCs were set at the same temperature [41], and the control of the loop operating temperature can shift from one CC to the other which depends on the actually heat load distribution between two evaporators [42].

Hoang and $\mathrm{Ku}$ [1] conducted extensive experimental research for four-evaporator LHPs based on a new design with capillary-links among multiple CCs. The four-evaporator LHP layout and thermocouple locations were shown in Fig. 6. E1 was the nearest to and E4 was the farthest from the condenser. The processes of how the control of operation temperature of four-evaporators LHP switched among four CCs with individual evaporator heat loads (case 1) and with combinations of multi-evaporator heat loads (case 2 and case 3) were described. Table 2 shows the heater power matrix of three typical cases. E1, E2, E3 and E4 represent Evaporator 1, 2, 3 and 4, respectively. In Figs. 7-9 the loop operation temperature control switch process is displayed among four CCs at three corresponding cases, with data from Hoang and $\mathrm{Ku}[1]$.

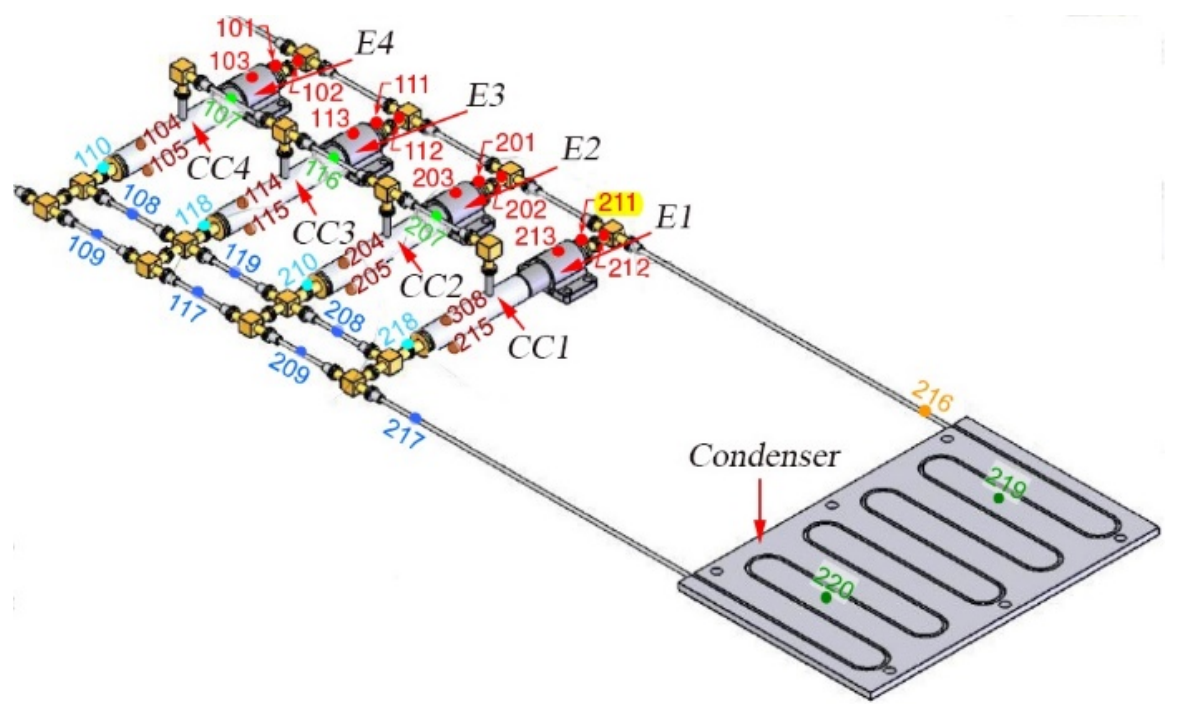

Fig. 6 The layout of four-evaporator LHP [1]

For case 1 shown in Fig. 7, only E1 was heated and the chiller set point was $-10^{\circ} \mathrm{C}$. Before E1 heater power reached 20W, CC1 controlled the loop saturation and other CCs liquid-filled with much lower temperatures. When E1 heater power was stepped up to 20W, CC1 lost control of the loop saturation by a decrease of its temperature with $2.1^{\circ} \mathrm{C}$. CC3 took over the control of saturation with a temperature increase of $3.2^{\circ} \mathrm{C}$. It was the CC3 not CC2 that was located closer to CC1 to control the loop temperature, because more liquid was accumulated in CC2 by the capillary links to 
supply liquid to E1 wick, leading to a liquid-filled condition of CC2. CC4 kept liquid-filled due to the least heat sharing from E1 and the heat loss with ambient with the longest loop length. With the E1 heater power 30W/40W/50W stepped up, CC3 still controlled the saturation temperature despite the temperatures increase with power. The loop operation with step-down of E1 power repeated that in the corresponding steps during the power step-ups despite the temperatures were higher. When E1 power decreased to $10 \mathrm{~W}$, the control of loop saturation was switched from E3 to E1. There was not much difference between E2, E3, E4 individual tests and E1 tests with the exception of higher saturation temperatures. The saturation temperature in the E4 individual test was highest among the individual tests.

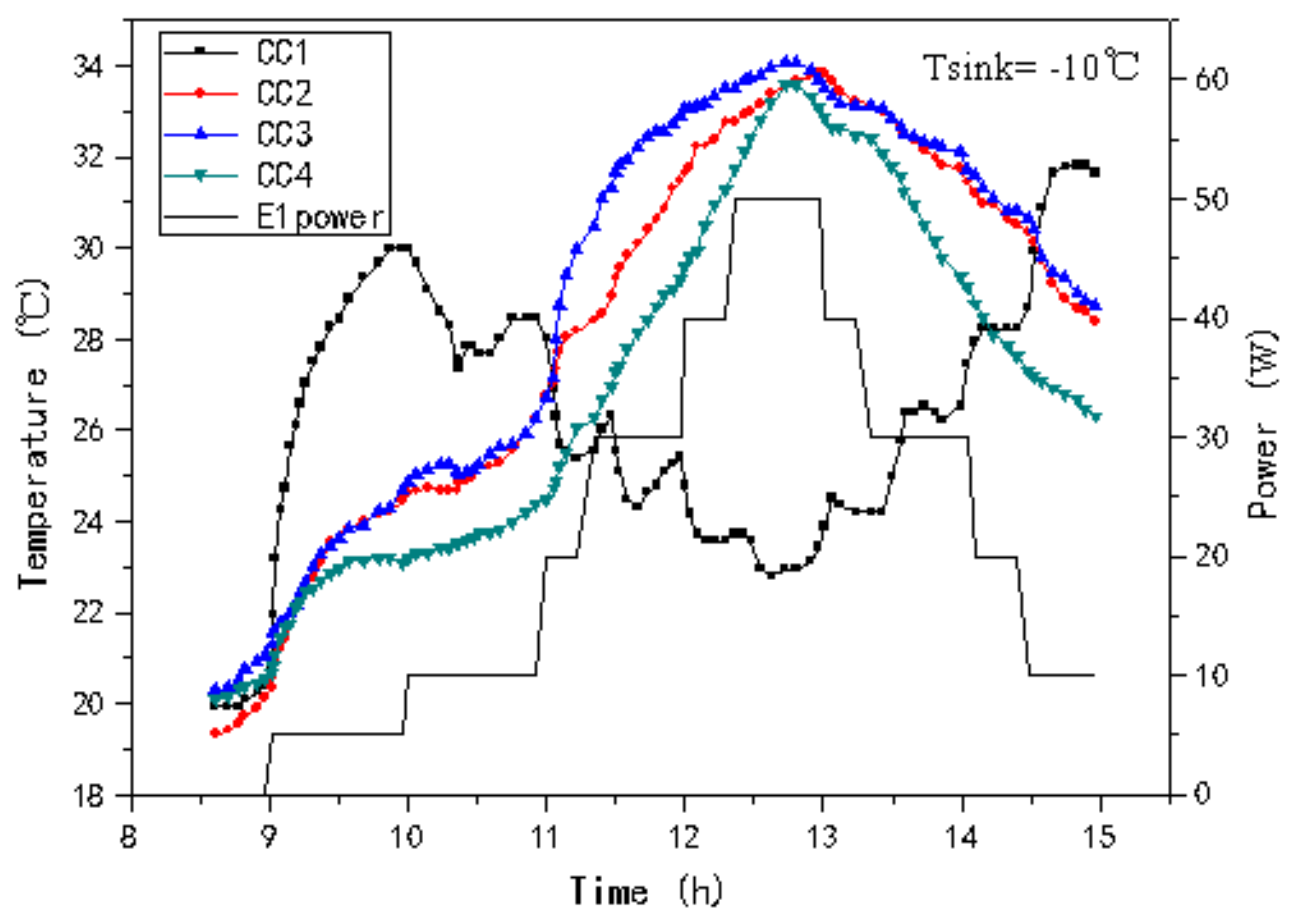

Fig. 7 Four evaporator LHP operation temperature control among four CCs with E1 power variation--case1 (drawn by the authors with data from Hoang and Ku [1])

For case 2 shown in Fig. 8, four evaporators were heated with even power of $10 \mathrm{~W}$ to start-up. CC4 controls the loop saturation temperature since E4 was farthest from the liquid line and received the least subcooling. With E4 power stepped down from $10 \mathrm{~W}$ to $5 \mathrm{~W}$ and E1 power stepped up to 15W, CC4 still controlled loop temperature. When E4 power turned off and E1 power stepped up to 20W, CC3 instead of CC4 controlled loop temperature and sustained the control right during E3 power stepped down further to $5 \mathrm{~W}$ and E1 power stepped further to 25W. When E3 power turned off and E1 power stepped up to $30 \mathrm{~W}$, CC2 instead of CC3 control loop temperature and sustained the control right during E2 power stepped down further to $5 \mathrm{~W}$ and E1 power stepped further to $35 \mathrm{~W}$. When E1 power stepped up to $40 \mathrm{~W}$, further $50 \mathrm{~W}$, and 
E2/E3/E4 all turned off, just as case 1 only one evaporator powered, it is CC2 not CC3 in case 1 to control the operation temperature. Therefore, the operation temperature control may be different even in the same power scenario because the distribution of heat load among CCs is dynamic and influenced by foregoing thermal conditions.

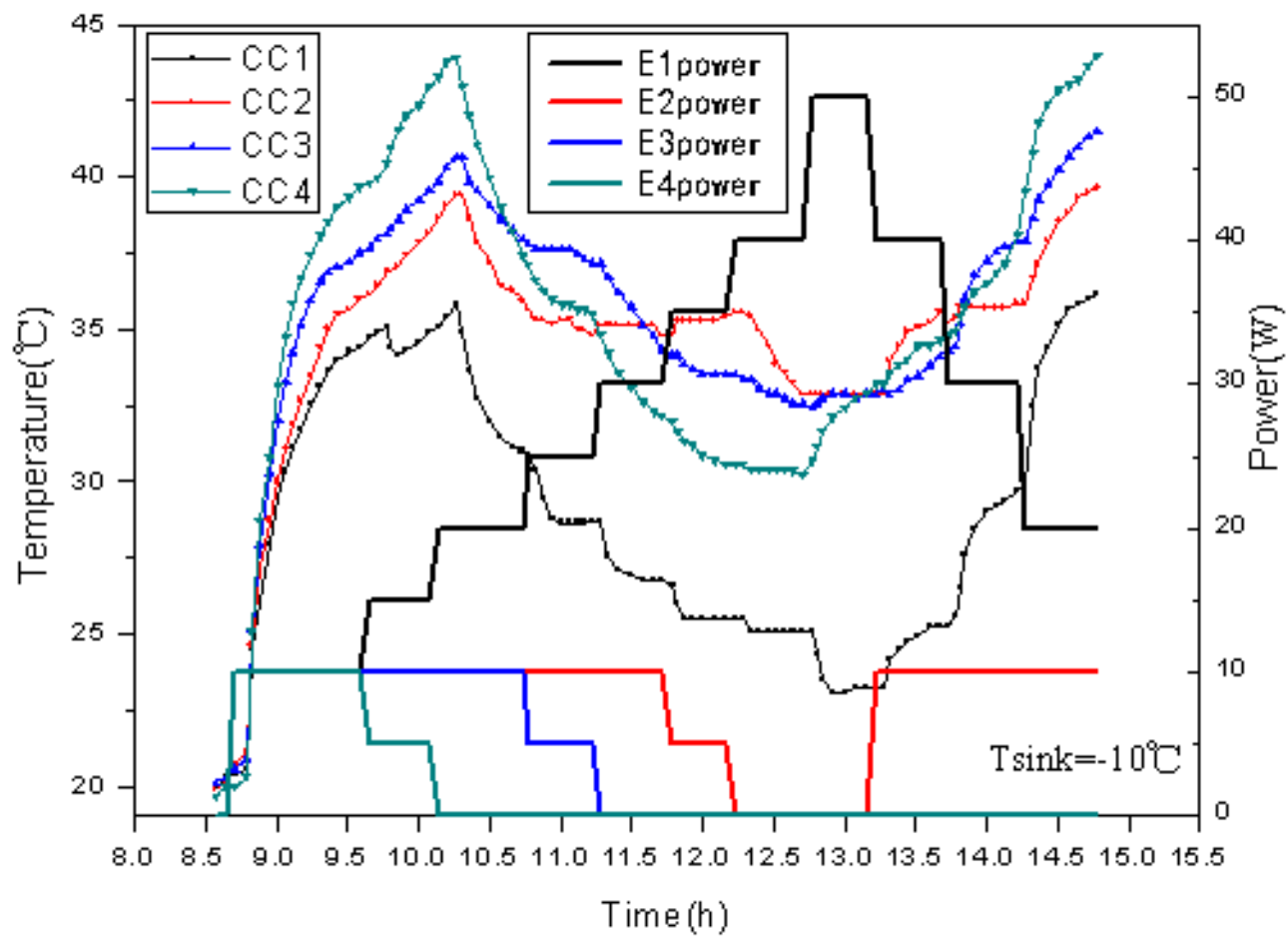

Fig. 8 Four evaporator LHP operation temperature control among four CCs with multi-evaporator power variation-case 2 (drawn by the authors with data from Hoang and $\mathrm{Ku}$ [1])

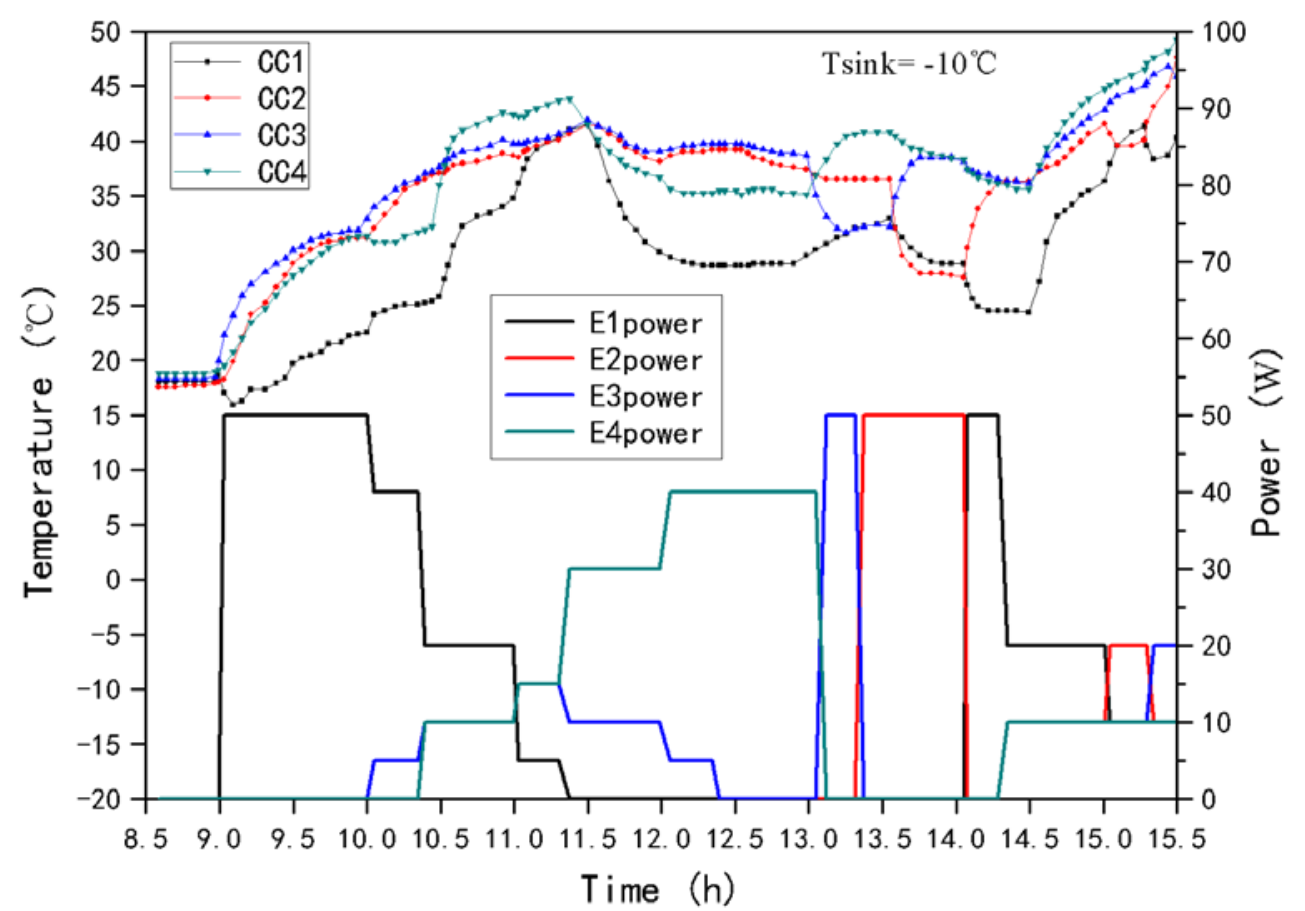

Fig. 9 Four evaporator LHP operation temperature control among four CCs with multi-evaporator 
power variation-case 3 (drawn by the authors with data from Hoang and $\mathrm{Ku}$ [1])

For case 3 shown in Fig. 9, LHP start-up with high power of $50 \mathrm{~W}$ applied to E1. The saturation temperature was controlled by CC3. With the combination variation of E1/E2/E3/E4 power, the control of loop operation temperature always switched from CC3 and CC4. During t=14-14.5h (that is 14:00 p.m. to $14: 30$ p.m.), CC3 or CC4 hardly controlled the loop temperature due to their similar temperatures. After $\mathrm{t}=$ 14.5h, a sudden and large increase of CC2 and CC3 temperatures occurred indicating that the capillary limits of E2 and E3 were obtained sequentially.

From the aforementioned literature analysis, the definite mechanisms that when and how the control rights of ME-LHP saturation temperature switched among multiple CCs await for further explanation theoretically and quantitatively. In the present, the ME-LHP operating temperature can be primarily determined by the following methods for two cases. 1) If there is no active measure to control the CC temperatures, the CC that reaches the highest temperature will contain a two-phase fluid and control the loop operating temperature. All other CCs will be liquid-filled [11]. The simplest way to judge the phase state in CCs is to observe the temperature variation of CCs in tests. Typically, the CC that controlled the loop operating temperature always showed a uniform temperature, while the CCs that were flooded with liquid always showed divergent temperatures [42]. 2) If all CCs are controlled at the same set-point temperature, the CC that has the lowest absolute pressure will control the loop operating temperature and all other CCs will be liquid-filled under most circumstances [41]. 3) For dual evaporators subject to even heat load, the evaporator that first starts up will take the lead of the operation conditions while the other will follow it [45].

\subsection{Heat Load Sharing}

The evaporator with no heat load can share the heat of other heat-loaded evaporators because the capillary pressure generated in the powered evaporator will drive the vapor flow to the cold and low pressure unpowered evaporator. This is referred to as heat load sharing [39-40].

$\mathrm{Ku}$ [43] presented a theoretical analysis and ground tests of heat load sharing operation for dual-evaporator LHP. There are two operating modes for ME-LHP: the normal operation mode and the heat load sharing mode. In the normal operation mode shown in Fig. 10a, the vapors generated by both heated evaporators converged at point 5 and condensed in both condensers. In the heat load sharing mode shown in Fig. 
10b, E2 was applied heat load and E1 shared the heat load. The vapor generated in E2 will flow to both condensers and E1. E1 at this moment functioned as a condensing evaporator. Therefore, the loop pressure drop via E1 in normal operation mode is larger than that in the heat sharing mode.

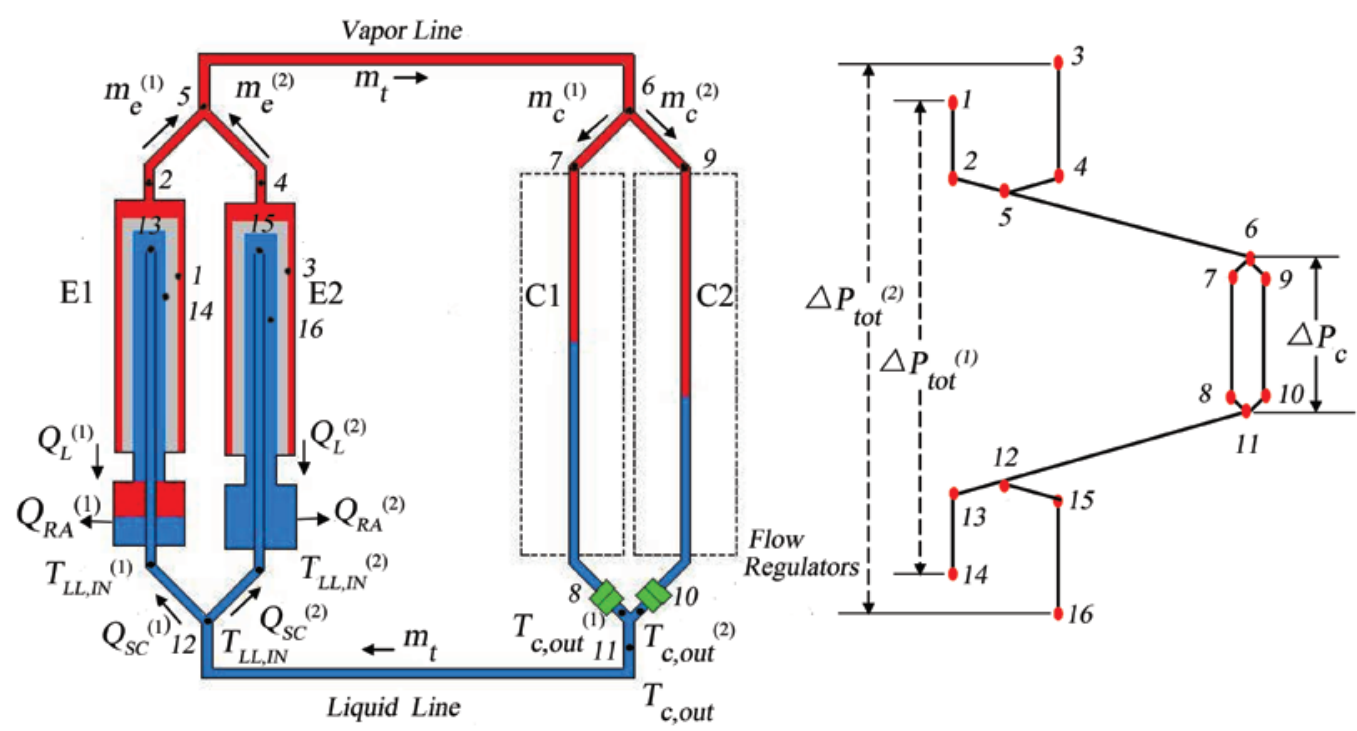

(a) Normal operation mode (Heat load to both evaporators)
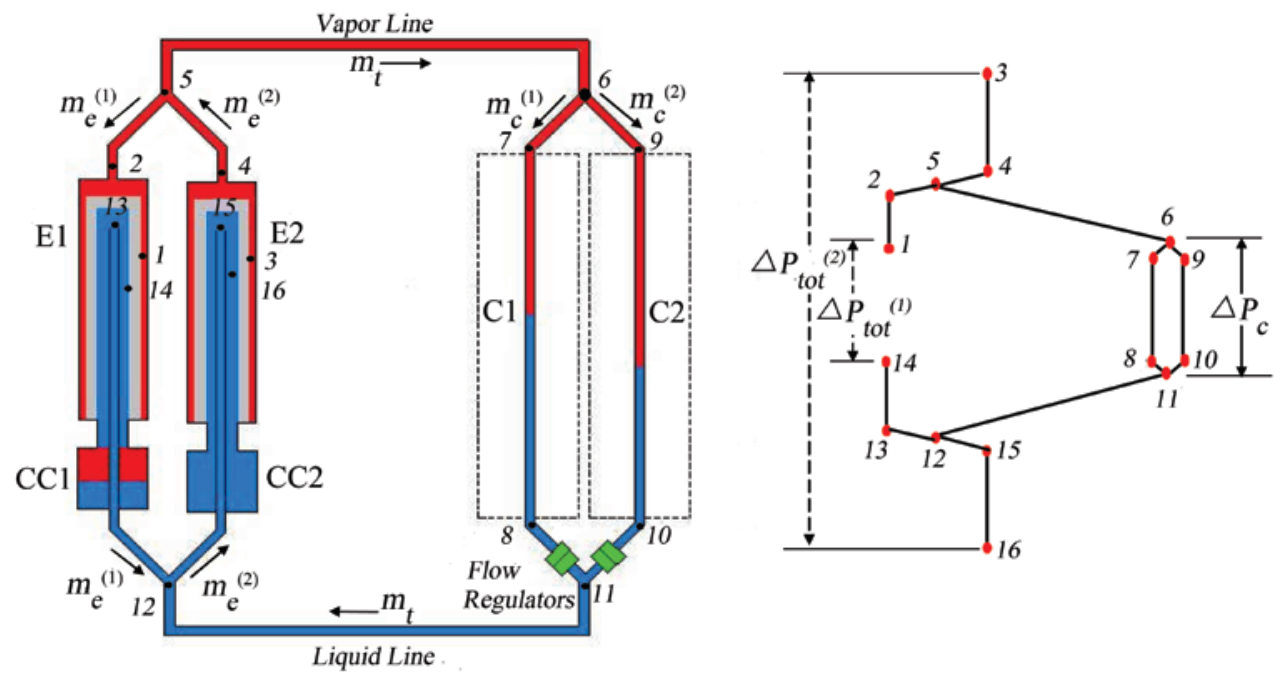

(b) Heat load sharing mode (Heat load to E2 only)

Fig. 10 Pressure drop diagram in an two-evaporators and two condensers LHP [43]

The experimental research on dual-evaporator LHP heat sharing function was also conducted with the influence of four factors, which are the applied heat loads, the sink temperature of the evaporator working in the condenser mode (E1_sink or E2_sink), CC set point temperature and condenser sink temperature. Table 3 summarizes the heat sharing amount varying with the above four influence factors at 7 experimental cases. Taking No.1 case as an example, when CC2 was controlled at 303K, E2 sink and two condenser sinks temperature were respectively kept at $293 \mathrm{~K}$ and $283 \mathrm{~K}$, and 
E1 power varied between $100 \mathrm{~W}$ and 20W with a decrement of 20W, heat shared by E2 decreased with a decreasing E1 power with the highest heat sharing value about $32 \mathrm{~W}$ at $\mathrm{E} 1=100 \mathrm{~W}$ and the lowest value about $1 \mathrm{~W}$ at E1=20W. From the experimental results summarized in Table 3, it can be found that the heat shared by the evaporator was mainly a function of the heat load applied to the other evaporator, the sink temperature of the evaporator sharing the heat, and was much less affected by the condenser sink temperatures. The amount of heat shared by one evaporator increased with an increasing applied heat load on the other evaporator and a decreasing evaporator sink temperature. The amount of heat shared by one evaporator also decreased as another CC set point temperature decreased. Once the sink temperature of the evaporator sharing the heat is higher than LHP saturation temperature, the evaporator would automatically switch the operation modes from heat-sharing mode (condenser) to normal mode (evaporator) thereby with a negative heat sharing value

Table 3 Amount of heat being shared varied with four influence factors [43]

\begin{tabular}{|c|c|c|c|}
\hline \multicolumn{2}{|c|}{ Experimental cases } & \multirow{2}{*}{$\begin{array}{c}\text { Influence factors } 1 \\
\text { Applied heat load (W) } \\
\text { E1=100/80/60/40/20/100 }\end{array}$} & \multirow{2}{*}{$\begin{array}{l}\begin{array}{l}\text { Heat sharing value } \\
\text { (W) }\end{array} \\
1 \sim 32\end{array}$} \\
\hline No.1 & $\begin{array}{l}\mathrm{CC} 2=303 \mathrm{~K} \\
\mathrm{C} 1=\mathrm{C} 2=283 \mathrm{~K} \\
\mathrm{E} 2 \_ \text {sink }=293 \mathrm{~K}\end{array}$ & & \\
\hline No.2 & $\begin{array}{l}\mathrm{CC} 1=303 \mathrm{~K} \\
\mathrm{C} 1=273 \mathrm{~K}, \mathrm{C} 2=293 \mathrm{~K} \\
\mathrm{E} 2 \_ \text {inlet }=288 \mathrm{~K}\end{array}$ & $\mathrm{E} 1=125 / 100 / 75 / 50 / 25 / 50$ & $8 \sim 42$ \\
\hline No.3 & $\begin{array}{l}\text { No active CC } \\
\text { temperature control } \\
\text { C1=C2=283K } \\
\text { E2_inlet }=293 \mathrm{~K}\end{array}$ & $\mathrm{E} 1=100 / 80 / 60 / 40 / 20 / 100$ & $1 \sim 21$ \\
\hline \multicolumn{2}{|c|}{ Experimental cases } & $\begin{array}{c}\text { Influence factors } 2 \\
\text { Evaporator Sink Temperature (K) }\end{array}$ & $\begin{array}{c}\text { Heat sharing value } \\
\text { (W) }\end{array}$ \\
\hline No.4 & $\begin{array}{l}\mathrm{CC} 1=303 \mathrm{~K} \\
\mathrm{E} 2=100 \mathrm{~W}\end{array}$ & E1_sink= 293/288/283/298/303 & $-4 \sim 50$ \\
\hline No.5 & $\begin{array}{l}\text { No active CC } \\
\text { temperature control, } \\
\text { E2=100W }\end{array}$ & $E 1 \_\operatorname{sink}=293 / 288 / 283 / 298 / 303$ & $-18 \sim 40$ \\
\hline \multicolumn{2}{|c|}{ Experimental cases } & $\begin{array}{c}\text { Influence factors } 3 \\
\text { CC Set Point Temperature (K) }\end{array}$ & $\begin{array}{c}\text { Heat sharing value } \\
(\mathrm{W})\end{array}$ \\
\hline No.6 & $\begin{array}{l}\text { E1=100W } \\
\text { E2_sink= 283K }\end{array}$ & $\begin{array}{l}\text { CC1 }=303 / 298 / 293 / \\
288 / 286 / 283 / 288 / 292 / 293 \\
\end{array}$ & $15 \sim 45$ \\
\hline \multicolumn{2}{|c|}{ Experimental cases } & \begin{tabular}{c|} 
Influence factors 4 \\
Condenser heat sink (K) \\
\end{tabular} & $\begin{array}{c}\text { Heat sharing value } \\
\text { (W) }\end{array}$ \\
\hline No.7 & $\begin{array}{l}\mathrm{CC} 1=\mathrm{CC} 2=303 \mathrm{~K} \\
\mathrm{E} 2=100 \mathrm{~W}\end{array}$ & $\begin{array}{l}\text { C1/C2=273/273, 293/273, } \\
\text { 293/283,298/283 }\end{array}$ & $15 \sim 45$ \\
\hline
\end{tabular}




\section{E1_sink= 283K}

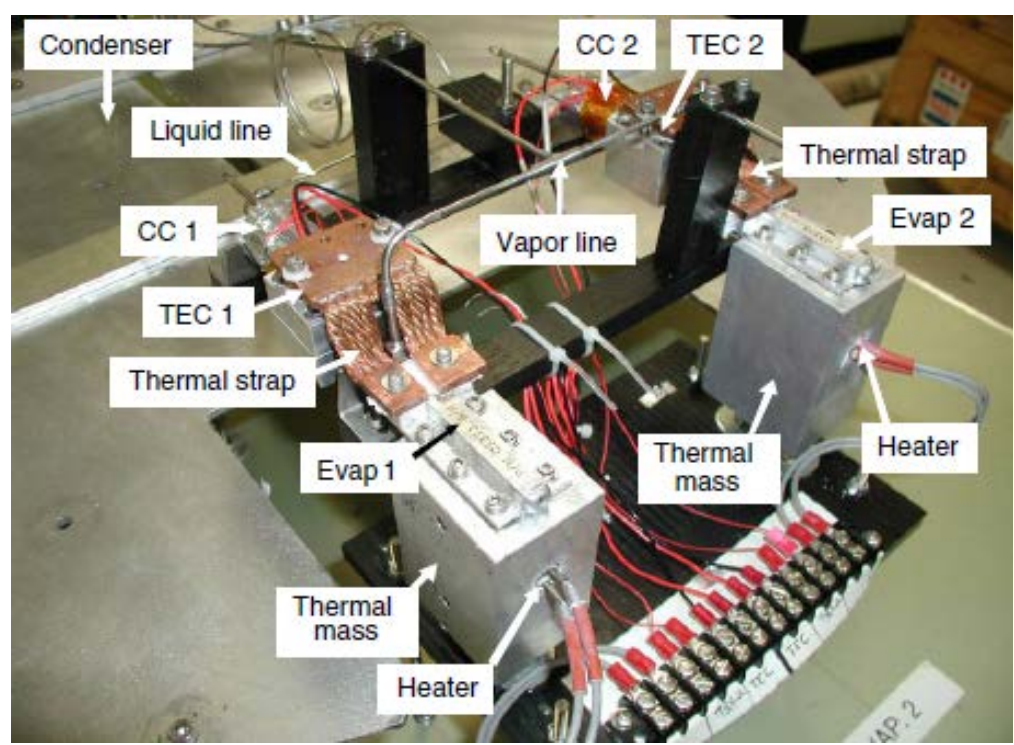

Fig. 11 2E-2C MLHP in heat-load sharing test [15]

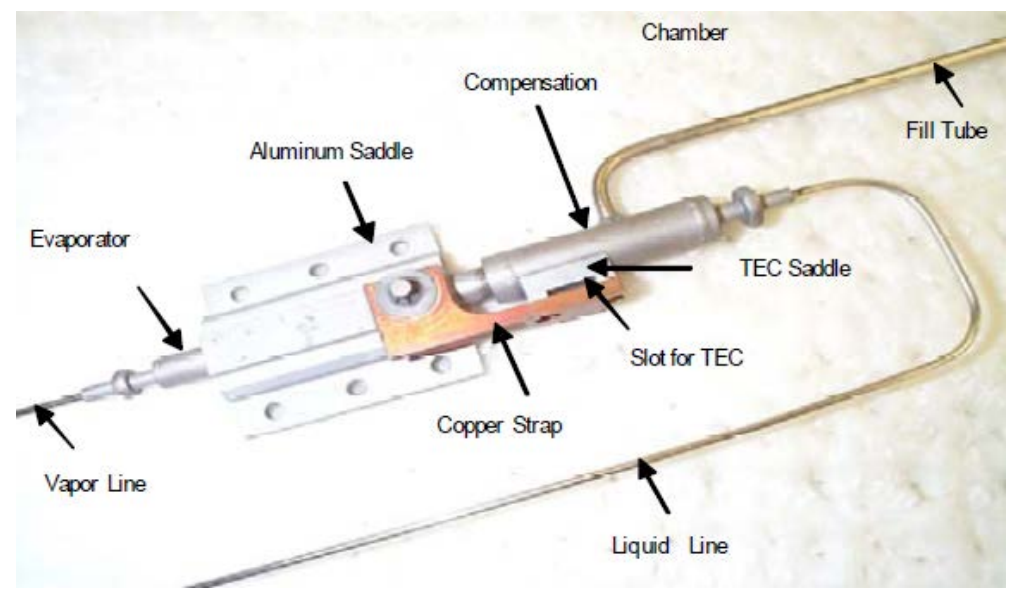

Fig. 12 Typical setup of TEC in LHP [52]

$\mathrm{Ku}$ [15] calculated the amount of heat load sharing of 2E-2C LHP by measuring the flow rate and the temperatures at the inlet and outlet ends of the fluid flow through the evaporator thermal mass as shown in Fig. 11. Two chillers were used to cool the evaporator thermal masses, but only one chiller was needed for any given heat-load sharing test. Thermoelectric converter (TEC) was installed on the CC and connected to the evaporator via a copper thermal strap. Fig. 12 shows the typical installation of TEC in LHP. Either the TEC or the electric heater was used to control the CC temperature for a given test but not both. Fig. 13 shows the measured temperatures of 2E-2C LHP in a heat-load sharing test with E1 $=0 \mathrm{~W}$ and E2 $=50 \mathrm{~W}$, which were also used to compare with the predicted results. The predicted results were computed by the analytical model earliest developed by Hoang and Ku [36] and later developed by J. Ku et al. [7,16], which has been illustrated in Section 3. In Fig. 13, the temperature 
of the circulating fluid through E1 thermal mass increased gradually while the mass flow rate remained unchanged after successful start-up of LHP. This means that E1 is in the condenser mode and heat-load sharing from E2. The amount of E1 heat load sharing decreased with the temperature increase of circulating fluid. When the circulating fluid temperature was raised above the CC saturation temperature, the heat being shared of E1 became negative and the E1 automatically switched to the evaporator operation mode.

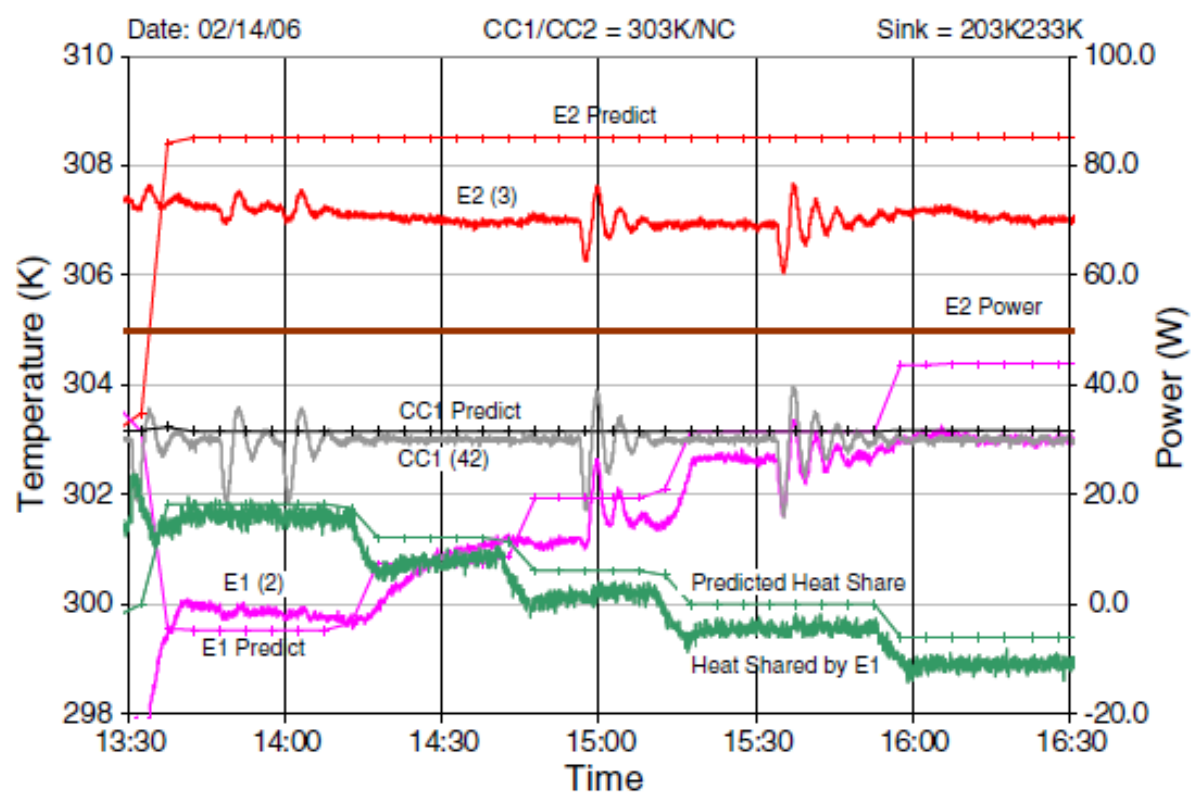

Fig. 13 Loop temperature in heat load sharing test E1/E2=0/50W [15]

Hoang [1] conducted four evaporators LHP tests and pointed out that the overall thermal conductance of the ME-LHP was reduced when the loop operated in a heat-load sharing mode. The reason was that the mass flow to the inactive evaporators brought back warm liquid to the active ones, decreasing the amount of overall subcooling for the loop. Okutani et al. [17] provided an equation to calculate the amount of heat shared by one evaporator for modeling the LHP with dual evaporators and dual condensers with PTFE wicks. Their equation needs to be firstly preset with an evaporator heat transfer coefficient, which determines the accuracy of the equation.

From the aforementioned review, heat load sharing is an inherent function of an LHP with multiple evaporators. Heat load sharing among evaporators is passively and automatically accomplished through internal vapor distribution among the evaporators. The load is automatically distributed between multiple evaporators and condensers according to the conservation laws. The amount of heat shared by an unheated evaporator is mainly affected by the system heat load, the sink temperature of the 
condensing evaporator, and much less affected by the condenser sink temperature. If the CC temperature is controlled, the amount of heat shared by one evaporator also varies directly with another CC set point temperature. Heat load sharing feature also benefits space thermal control because it will eliminate the need for supplemental electrical heaters while maintaining all instruments close to the loop operating temperature.

\subsection{Capillary limit}

The capillary limit can be identified by a sudden and large increase of the loop operating temperature. No matter LHP has single or multiple evaporators, the experimental results have proven that when capillary limit is exceeded by a small margin, LHP will still continue to function at a higher temperature. Moreover, LHP can recover from a partial dry-out by reducing the heat load without restart $[6,11$, 41-42, 46-48].

Nagano [5] theoretically analyzed the effect of various parameters on the capillary limit of an LHP with two evaporators and two condensers when the heat load applied to both evaporators and only one evaporator. Due to the characteristics that evaporator core can tolerate vapor, not like capillary pump loop (CPL), LHP can reach a new steady state even after the system total pressure drop is equal to the capillary limit at a given set point temperature (i.e., capillary limit is exceeded). This has been verified by $\mathrm{Ku}$ and Birur [41]. Hence, the concept of heat transport limit of LHP becomes more ambiguous but transport limit is a function of operational temperature for both single and multiple evaporators LHP. Fig. 10 depicted the fluid flow and the corresponding pressure drop for LHP with two evaporators and two condensers. In the case of heat load applied on both evaporators, the pressure drop from the vapor line to the liquid line via condensers is common to both evaporators and is a function of the total heat load applied to the two evaporators. The pressure drops from the outer diameter of wick to the vapor line and from the liquid line to the inner diameter of wick are dependent upon the corresponding heat load to each evaporator. Thus the total pressure drop imposed upon each evaporator is a function of the total heat load and the heat load distribution between two evaporators. In the case of heat load applied to only one of the evaporators, the evaporator receiving no heat load will work as a condenser. The flow from the liquid line to the vapor line is reversed via evaporator instead of condenser. Consequently the pressure drop that the wick in this unheated evaporator has to sustain could be significantly reduced compared to the case of a heated evaporator. The capillary limits of DE-LHP with different wick 
materials in each evaporator were tested by different researchers [11, 41-42]. The evaporator with a titanium wick showed three times weaker in capillary limit than the evaporator with a nickel wick. The capillary limit tested in open literatures for LHP with two evaporators is 240W in Chang and Nagano [44], $120 \mathrm{~W}$ in Ku and Ottenstein [39], 110-140W in Maydanik et al. [34], $100 \mathrm{~W}$ for miniature 2E-2C-LHP with 8mm evaporator diameter in Habtour [49], 120-140 W for 2E-2C-LHP with evaporator outer diameter of $15 \mathrm{~mm}$ in $\mathrm{Ku}$ [50].

From the above review, ME-LHP capillary limit rests on three factors: the operational temperature, the total heat load and the heat load distribution among multiple evaporators. The latter two factors play important roles in the pressure losses of ME-LHP components. The more heat leakage from evaporator to CC, the lower capillary limit reached at certain operation temperature. The heat leak was influenced by the thermal conductance between the evaporator core and the outer surface of wick [51]. And the thermal conductance is highly dependent upon the liquid-vapor phase state in the evaporator core. The higher the vapor void fraction, the larger the heat leak. Vapor penetration will first occur in the largest pore which results in the decrease of surface tension and viscosity of fluid with the increase of operating temperature. Therefore, the material and pore size of the wick also affect the ME-LHP capillary limit. Normally for ME-LHP, a new steady state could be reached at a higher operating temperature if the capillary limit is not exceeded by too much. In addition, the heat transport capacity in dual evaporators subject to even heat load is larger than that in single evaporator subject to heat load.

\section{Effect of required superheat on ME-LHP start-up}

Start-up is a complicated dynamic process of working fluid circulation and redistribution combined with phase change such as evaporation, condensation, and nucleate boiling. Self-starting with no assistance is the typical characteristic of LHP distinctive from other close systems of two-phase circulation. However, certain required superheat is the precondition to successful start-up. The "degree of superheat" is technically defined as the liquid temperature in grooves minus the current saturation temperature (the equilibrium value at the current pressure) at the point of start-up, but practically it can be measured as the evaporator case temperature minus the compensation chamber temperature. Many factors influence the degree superheat: case and wick materials, working fluids, temperature interval (together with the fluid properties), surface treatments and manufacturing methods, cleanliness, non-condensable gas, vibration level, prior history (how subcooled the grooves were and for how long), etc. 
There are three LHP start-up scenarios based on the required superheat as shown in Fig. 14 [7]. When evaporator temperature rises above the CC temperature by a certain amount, vapor bubbles will generate in the evaporator and the LHP can start as shown in Fig. 14a. When a low heat load applied to the evaporator and a high superheat is required, the LHP start-up becomes difficult because the CC temperature will rise in tandem with evaporator and the superheat cannot obtain due to the heat leak between them as shown in Fig. 14b. Two measures can overcome the start-up difficulty. One method is to generate highly concentrated heat flux using a smart heater to generate the liquid boiling in evaporator vapor groove. The required starter heater power is in the range of $30 \mathrm{~W}$ to $60 \mathrm{~W}$ for standard LHPs with a $25 \mathrm{~mm}$-outer-diameter evaporator. For LHPs with small evaporators, the required starter heater power is estimated to be between $20 \mathrm{~W}$ and $40 \mathrm{~W}$. The other method is to cool and maintain a constant CC temperature using the attached thermoelectric converter (TEC) no matter how high the required superheat and how low the heat load are. This scenario is shown in Fig. 14c.

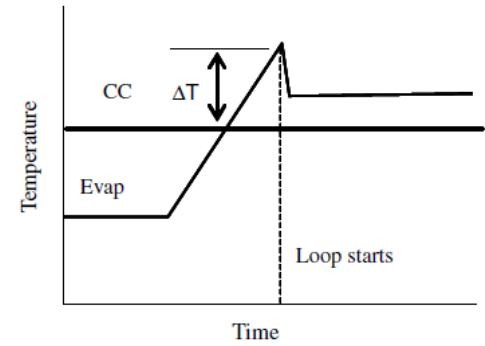

a)

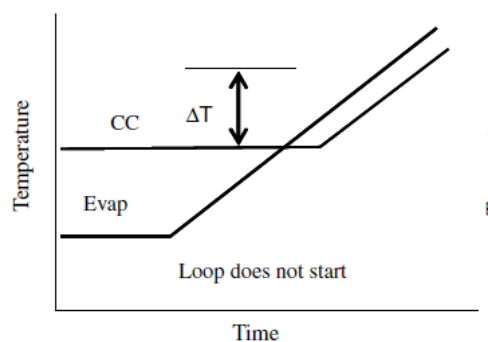

b)

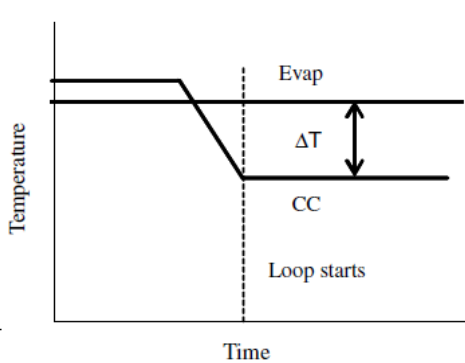

c)

Fig. 14 LHP start-up scenarios [7]

Superheat value is a key input parameter in analysis of LHP models. However, there is no general way to predict the degree of superheat that is experienced in any unit in any given circumstances [20]. Therefore, the suitable experimental superheat value in the similar LHP configurations was often used as the input value for LHP start-up modeling. The superheat values for ME-LHP at different heat load power and applying modes, different CC set-point temperature and sink temperature were summarized in Table 4. It is found that the superheat value can be zero, indicating that the ME-LHP immediately start-up after heat load applied to evaporator, meanwhile, the superheat can be over $10 \mathrm{~K}$ if the evaporator is in the least desired fluid distribution situation during start-up. This stochastic characteristic of superheat values just testified the viewpoint of $\mathrm{Ku}$ et al. [7], who pointed out that the stochastic superheat value can range from less than $1 \mathrm{~K}$ to more than $10 \mathrm{~K}$. 
Table 4 ME-LHP start-up superheat

\begin{tabular}{|c|c|c|c|c|c|c|}
\hline $\begin{array}{l}\text { LHP } \\
\text { type }\end{array}$ & $\begin{array}{l}\text { Power } \\
\text { (W) }\end{array}$ & $\begin{array}{l}\text { Evaporator temp. } \\
\left({ }^{\circ} \mathrm{C}\right)\end{array}$ & $\begin{array}{l}\text { CC active } \\
\text { control }\left({ }^{\circ} \mathrm{C}\right)\end{array}$ & $\begin{array}{l}\text { Sink Temp. } \\
\left({ }^{\circ} \mathrm{C}\right)\end{array}$ & $\begin{array}{l}\text { Superheat } \\
\left({ }^{\circ} \mathrm{C}\right)\end{array}$ & Ref. \\
\hline \multirow{2}{*}{$2 \mathrm{E}-2 \mathrm{C}$} & E1/E2:50/5 & E1:23 & 20 & -100 & 3 & \multirow{2}{*}{ [15] } \\
\hline & E1/E2:0/10 & $\mathrm{E} 2: 21$ & 20 & -100 & 1 & \\
\hline $2 \mathrm{E}-2 \mathrm{C}$ & $\mathrm{E} 1 / \mathrm{E} 2: 10 / 0$ & $\mathrm{E} 1: 10$ & $0 / 0$ & -50 & 10 & [39] \\
\hline protoflig & E1/E2:0/10 & $\mathrm{E} 2: 8$ & $0 / 0$ & -50 & 8 & \\
\hline \multirow[t]{4}{*}{ ht } & $\mathrm{E} 1 / \mathrm{E} 2: 0 / 50$ & $\mathrm{E} 2: 3$ & $0 / 0$ & -50 & 3 & \\
\hline & $\mathrm{E} 1 / \mathrm{E} 2: 5 / 0$ & $\mathrm{E} 1: 22$ & $20 / 20$ & I & 2 & \\
\hline & $\mathrm{E} 1 / \mathrm{E} 2: 5 / 5$ & E1/E2:22.2/22.5 & $20 / 20$ & / & $2.2 / 2.5$ & \\
\hline & $\mathrm{E} 1 / \mathrm{E} 2: 5 / 50$ & $\mathrm{E} 1 / \mathrm{E} 2: 25 / 25$ & $25 / 25$ & l & $0 / 0$ & \\
\hline \multirow[t]{6}{*}{$4 \mathrm{E}-1 \mathrm{C}$} & E1/E2/E3/E4:5/0/0/0 & $\mathrm{E} 1: 29$ & I & -10 & 8 & {$[1]$} \\
\hline & E1/E2/E3/E4:0/5/0/0 & $\mathrm{E} 2: 29$ & / & -10 & 10 & \\
\hline & \multirow[t]{2}{*}{ E1/E2/E3/E4:10/10/10/10 } & E1/E2/E3/E4:36/3 & l & -10 & $14 / 15 / 10 /$ & \\
\hline & & 7/39/38 & & & 14 & \\
\hline & E1/E2/E3/E4:50/0/0/0 & $\mathrm{E} 1: 21.5$ & / & -10 & 5.5 & \\
\hline & E1/E2/E3/E4:50/0/0/0 & $\mathrm{E} 1: 21.5$ & I & -20 & 5 & \\
\hline
\end{tabular}

As shown in previous sections, certain superheat and heat load to the evaporators are requisite conditions for LHP successful start-up. These parameters are usually used to evaluate how easily and successfully LHP start-up. However, the amounts of above parameters are stochastic and highly rely on the initial liquid/vapor distribution in the evaporator core and the vapor grooves. Take the parameter of required superheat as an example, if the vapor is present in the vapor grooves, liquid will evaporate and boiling at small superheat due to the nucleation sites effects. If the grooves are completely filled with liquid, however, liquid boiling requires larger superheat.

Presently, it is widely recognized that there are four possible liquid/vapor distribution situations prior to LHP start-up in the evaporator core and vapor grooves [47, 52-54]. $\mathrm{Ku}$ [52] and Entremont [54] depicted the thermal response to initial evaporator liquid distribution. Wang et al. [53] summarized the characteristics of four cases of fluid distribution. Ku [55] and Zhang [56] illustrated the methods how to realize four cases of fluid distribution in LHP evaporator during LHP tests by adjusting the tilt between evaporator and CC, combined with the control of LHP pre-conditions. Wang et al. [53] pointed out that proper controlling the initial liquid-vapor condition in evaporator core definitely benefits the LHP start-up success. Moreover, heat leakage from the evaporator to CC, as one of the present research focuses in LHP, is also strongly dependent upon the vapor void fraction inside the evaporator core. Quite a number of LHP ground tests have been demonstrated that heat leakage is the most important 
factor in determining LHP low power operation. The optimization of the evaporator and CC assembly design has been taken to decrease the heat leakage. The majority of evaporator/CC assembly in LHP is concentric layout as shown in Fig. 15a. This type of layout will cause liquid puddle at the bottom of the CC while evaporator core could be mostly filled with vapor. A good attempt is to design an eccentric evaporator/CC assembly as shown in Fig. 15b, which can mitigate the liquid drainage issue in the CC, especially when CC has a larger diameter than evaporator [52, 57-58]. It also indicates that both evaporator-CC assembly design and fluid inventory computation can be considered for future ME-LHP design improvements and applications.

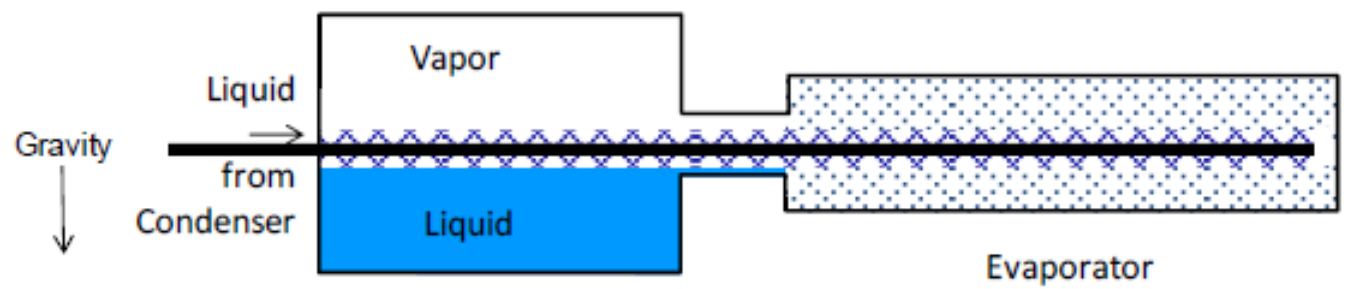

(a) Concentric layout

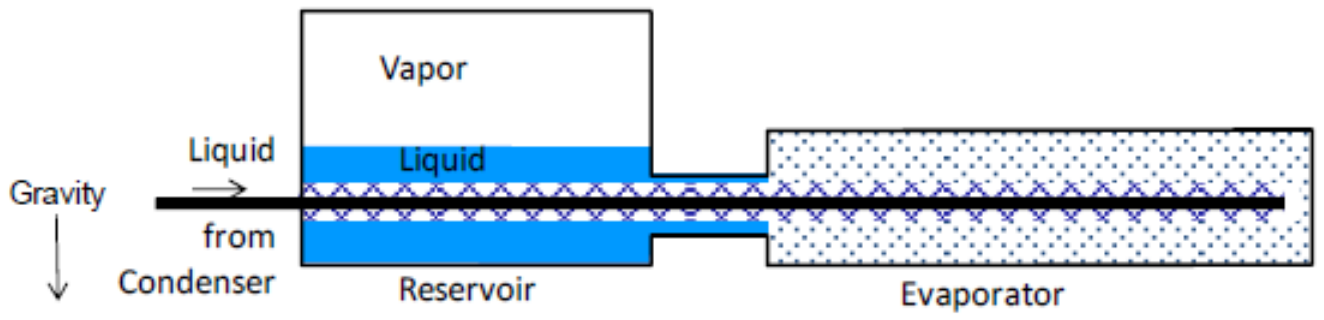

(b) Eccentric layout

Fig. 15 Evaporator/CC assembly in LHP [52]

In addition, the three peculiar behaviors in LHP including temperature hysteresis, temperature oscillation and temperature overshoot, are all influenced by the liquid-vapor distribution both in evaporators and CCs. The former one belongs to the steady operational performance and frequently occurs at low powers $(<200 \mathrm{~W})$. Low power hysteresis effect has been observed by many researchers [55, 59-62]. In ME-LHP, the two-phase dynamics is more complicated and further research is required to obtain insight to this phenomenon. Even though temperature hysteresis is not inevitable and may be regarded as a drawback of LHPs, there is a sufficiently wide range of heat loads at which hysteresis is not observed or weakly pronounced. Therefore, good control the thermal conditions to expand the stable heat load range without temperature hysteresis will be a research point for ME-LHP. Temperature oscillation and temperature overshoot are in the category of non-linear instability performance, frequently appearing during start-up. Temperature overshoot is considered as one of the main parameters to indicate if a LHP works normally and 
reliably or fails as a spacecraft thermal control device. J. Ku [52] discussed the overshoot and undershoot during LHP startup in detail. Temperature oscillations can occur in LHPs during both startup and normal operation, especially at comparatively low heat loads. A lot of research has been done in LHP temperature oscillations including the types [28, 63], the influencing factors [64], the mechanisms [65-67], and the control approaches of temperature oscillations [68]. Much research work in both experiments and modeling are required to reveal the mechanisms of above peculiar behaviors in ME-LHP.

\section{Conclusion}

The present review investigated the ME-LHP development status in the system design, primary mathematical models, the key issues in steady-state operation and start-up performance.

1) The feasibility of ME-LHP has been widely demonstrated by many experiments. The addition of multiple evaporators and condensers increased the complexity not only in ME-LHP system design, but also in the theoretical analysis due to the inherent thermo-hydraulic interactions. The number of evaporators is limited by a certain ratio between LHP components volume and the charged working fluid mass. Some new approaches to the ME-LHP design have been carried out with the goal of keeping the total CC volume not larger than that of the single evaporator LHP. At present, four evaporator LHP has been fabricated and tested to work well in typical conditions. The most widely adopted calculation method of CC volume and liquid inventory of ME-LHP is Goncharov et al. relations [9][13].

2) Modeling multiple evaporators/condensers LHP operation is an extremely hard work and until now only few computer codes are available for ME-LHP steady and transient simulation. This paper summarizes related theoretical works and typical ME-LHP models.

3) ME-LHP steady operational performance has been analytically reviewed. The operation temperature control of ME-LHP is much more complicated than conventional LHP. Two methods have been summarized to determine the ME-LHP operating temperature for two cases. Nonetheless, further explanation is required for the definite mechanisms of when and how the control rights of ME-LHP saturation temperature switched among multiple CCs. Experimental research works on heat sharing features were also summarized with four influencing factors, which are the system heat load, the sink temperature of the evaporator working in the condenser mode, the CC set point temperature and the condenser sink temperature. All the main ME-LHP research works published in 
the past 20 years were also summarized, covering the configuration of multi-evaporators and multi-condensers, the material of ME-LHP components, the working fluid, the wick material and the main steady-state operation results under different test conditions.

4) The significant factors to determine the ME-LHP start-up performance were investigated. The required superheat and its effects on different configurations of ME-LHP start-up were also given.

\section{Acknowledgments}

This work is supported by Natural Science Foundation of Shandong Province, China (No.ZR201702120003), the National Natural Science Foundation of China (No.51206189), and the UK Science and Technology Facilities Council. The authors greatly appreciate their financial support.

\section{References}

[1] T.T. Hoang, J. Ku, Multiple-Evaporator Loop Heat Pipe, in: 53rd AIAA Aerospace Sciences Meeting, American Institute of Aeronautics and Astronautics, Kissimmee, Florida, 2015.

[2] D. Bugby, K. Wrenn, D. Wolf, E. Kroliczek, J. Yun, S. Krein, D. Mark, Multi-evaporator Hybrid Loop Heat Pipe for Small Spacecraft Thermal Management, IEEEAC paper, 2005.

[3] D. Bugby, T. Miller, J. Baker, Multi-Evaporator Two-phase Loop Cooling System, in 4th International Energy Conversion Engineering Conference, San Diego, California, 2006.

[4] P. Helden, M. Ouden, N. Santos, R. Riehl, Novel Loop Heat Pipes Development for Ground and Space Applications, in: 18th International Congress of Mechanical Engineering, Ouro Preto, Brazil, 2005.

[5] Y.F. Maydanik, Loop Heat Pipes, Applied Thermal Engineering, 25(5) (2005) 635-657.

[6] H. Nagano, J. Ku, Capillary Limit of a Multiple-Evaporator and Multiple-Condenser Miniature Loop Heat Pipe, Journal of Thermophysics and Heat Transfer, 21(4) (2007) 694-701.

[7] J. Ku, L. Ottenstein, D. Douglas, T. Hoang, Technology Overview of a Multi-Evaporator Miniature Loop Heat Pipe for Spacecraft Applications, Journal of Spacecraft and Rockets, 49(6) (2012) 999-1007.

[8] S. Storring, Design and Manufacturing Of Loop Heat Pipes for Electronics Cooling, Master dissertation in Aerospace Engineering, Carleton University, 2006.

[9] K. Goncharov, O. Golovin, V. Kolesnikov, Loop Heat Pipe with Several Evaporators, in: 30th International Conference on Environmental Systems,SAE Technical Paper, Warrendale, Pennsylvania, 2000.

[10] J. Yun, D. Wolf, E. Kroliczek, T. Hoang, Multiple Evaporator Loop Heat Pipe, in: 30th International Conference on Environmental Systems, Warrendale, Pennsylvania ,2000.

[11] J. Ku, G.C. Birur, An Experimental Study of the Operating Temperature in a Loop Heat Pipe with Two Evaporators and Two Condensers, SAE Paper No.2001-01-2189, 2001.

[12] T. EASY2000, Moscow: Application Program Package Manual.

[13] K. Goncharov, O. Golovin, V. Kolesnikov, Multi-evaporator Loop Heat Pipe, AIP Conference 
Proceedings, 504(1) (2000) 778-784.

[14] S. Launay, V. Sartre, J. Bonjour, Parametric Analysis of Loop Heat Pipe Operation: A Literature Review, International Journal of Thermal Sciences, 46(7) (2007) 621-636.

[15] J. Ku, L. Ottenstein, D. Douglas, T. Hoang, Validation Design for a Multi-Evaporator Miniature Loop Heat Pipe for Spacecraft Applications, Journal of Spacecraft and Rockets, 49(6) (2012) 1008-1018.

[16] J. Ku, L. Ottenstein, D. Douglas, T. Hoang,Multi-Evaporator Miniature Loop Heat Pipe for Small Spacecraft Thermal Control - Part 1: New Technologies and Validation Approach, in: 48th AIAA Aerospace Sciences Meeting Including the New Horizons Forum and Aerospace Exposition, Orlando, Florida, 2010.

[17] S. Okutani, H. Nagano, S. Okazaki, H. Ogawa, H. Nagai, Operating Characteristics of Multiple Evaporators and Multiple Condensers Loop Heat Pipe with Polytetrafluoroethylene Wicks, Journal of Electronics Cooling and Thermal Control, 4(1) (2014) 22-32.

[18] Y. Matsuda, H. Nagano, S. Okazaki, H. Ogawa, H. Nagai, Visualization of Loop Heat Pipe with Multiple Evaporators under Microgravity, in: 45th International Conference on Environmental Systems, Bellevue, Washington , 2015.

[19] T.T. Hoang, J. Ku, Mathematical Modeling of Loop Heat Pipes with Mutiple Capillary Pumps and Multiple Condensers, Part I Steady State Simulations, in: 2nd International Energy Conversion Engineering Conference, American Institute of Aeronautics and Astronautics, Rhode Island, 2004.

[20] S. Zinna, Numerical Analysis of a Loop Heat Pipe for the Thermal Control of a Cryo-Cooler on the International Space Station, Ph. D Dissertation, Department of Mechanical Engineering, University of Bergarno, 2007.

[21] V. Buz, K. Goncharov, Modeling of LHP Performances by Means of Specialized EASY Package Program, in: 12th International Heat Pipe Conference, Moscow, Russia, 2002.

[22] B. Cullimore, J. Baumann, Steady State and Transient Loop Heat Pipe Modeling, SAE Technical Paper, 2000.

[23] Y.F. Maydanik, Loop Heat Pipes, Applied Thermal Engineering, 25(5-6) (2005) 635-657.

[24] T. Kaya, T.T. Hoang, Mathematical Modeling of Loop Heat Pipes and Experimental Validation, Journal of Thermophysics and Heat Transfer, 13(3) (1999) 314-320.

[25] T. Kaya, J. Goldak, Numerical Analysis of Heat and Mass Transfer in the Capillary Structure of a Loop Heat Pipe, International Journal of Heat and Mass Transfer, 49(17) (2006) 3211-3220.

[26] A.S. Demidov, E.S. Yatsenko, Investigation of Heat And Mass Transfer in the Evaporation Zone Of a Heat Pipe Operating by the 'Inverted Meniscus' Principle, International Journal of Heat and Mass Transfer, 37(14) (1994) 2155-2163.

[27] C. Figus, Y.L. Bray, S. Bories, M. Prat, Heat and Mass Transfer with Phase Change in a porous Structure Partially Heated: Continuum Model and Pore Network Simulations, International Journal of Heat and Mass Transfer, 42(14) (1999) 2557-2569.

[28] B. Siedel, Analysis of Heat Transfer And Flow Patterns in a Loop Heat Pipe: Modelling by Analytical and Numerical Approaches and Experimental Observations, Institut National des Sciences Appliquées de Lyon, 2014.

[29] S. Launay, V. Platel, S. Dutour, J. L. Joly, Transient Modeling of Loop Heat Pipes for the Oscillating Behavior Study, Journal of Thermophysics and Heat Transfer, 21(3) (2007) 487-495.

[30] M.A. Chernysheva, Y.F. Maydanik, Numerical Simulation of Transient Heat And Mass Transfer in a Cylindrical Evaporator of a Loop Heat Pipe, International Journal of Heat and Mass Transfer, 51(17) 
(2008) 4204-4215.

[31] T. Kaya, R. Pérez, C. Gregori, A. Torres, Numerical Simulation of Transient Operation of Loop Heat Pipes, Applied Thermal Engineering, 28(8) (2008) 967-974.

[32] M. Nishikawara, H. Nagano, T. Kaya, Transient Thermo-Fluid Modeling of Loop Heat Pipes and Experimental Validation, Journal of Thermophysics and Heat Transfer, 27(4) (2013) 641-647.

[33] T. Hoang, J. Ku, Transient Modeling of Loop Heat Pipes, in: 1st International Energy Conversion Engineering Conference, American Institute of Aeronautics and Astronautics, Portsmouth, Virginia, 2003.

[34] Y.F. Maydanik, V.G. Pastukhov, M.A. Chernyshova, A.A. Delil, Development and Test Results of a Multi-Evaporator-Condenser Loop Heat Pipe, in: AIP Conference Proceedings, 2003, pp. 42-48.

[35] X. Chang, H. Nagano, Mathematical Modeling Of Multiple Evaporators/Condensers Loop Heat Pipe Operation With Flow Regulator Under Various Operating Conditions, Journal of Thermal Science and Technology, 10(2) (2015) 1-16.

[36] T. Hoang, J. Ku, Mathematical Modeling of Loop Heat Pipes with Multiple Evaporators and Multiple Condensers, 3rd International Energy Conversion Engineering Conference, AIAA paper 2005-36942, 2005.

[37] W. Bienert, D. Wolf, M. Nikitkin, Y.F. Maidanik, Y. Fershtater, S. Vershinin, J.M. Gottschlich, Proof-of-feasibility of Multiple Evaporator Loop Heat Pipes, in: Sixth European Symposium on Space Environmental Control Systems, 400(1997) 393-399.

[38] Y. Maidanik, Y. Fershtater, V. Pastukhov, K. Goncharov, O. Zagar, Y. Golovanov, Thermoregulation of loops with capillary pumping for space use, SAE Technical Paper, 1992.

[39] J. Ku, L. Ottenstein, Thermal Vacuum Testing of a Proto-flight Miniature Loop Heat Pipe with Two Evaporators and Two Condensers, in: 42nd AIAA Thermophysics Conference, American Institute of Aeronautics and Astronautics, Honolulu, Hawaii, 2011.

[40] J. Ku, L. Ottenstein, D. Douglas, T . Hoang, Multi-Evaporator Miniature Loop Heat Pipe for Small Spacecraft Thermal Control - Part 2: Validation Results in: 48th AIAA Aerospace Sciences Meeting Including the New Horizons Forum and Aerospace Exposition, Orlando, Florida, 2010.

[41] J. Ku, G.C. Birur, Active Control of the Operating Temperature in a Loop Heat Pipe with Two Evaporators and Two Condensers, SAE Paper No.2001-01-2188, 2001.

[42] J. Ku, G.C. Birur, Testing of a Loop Heat Pipe with Two Evaporators and Two Condensers, SAE Paper No.2001-01-2190, 2001.

[43] J. Ku, Heat Load Sharing in Loop Heat Pipes with Multiple Evaporators and Multiple Condensers, in: 9th AIAA/ASME Joint Thermophysics and Heat Transfer Conference, American Institute of Aeronautics and Astronautics, San Francisco, California , 2006.

[44] X. Chang, H. Nagano, Experimental Investigation of Loop Heat Pipe with Two Evaporators/Two Condensers under Thermal Vacuum Condition, Journal of Applied Mathematics and Physics, 4(8) (2016) 1460-1469.

[45] R. Riehl, Thermal Performance And Development of a Dual Evaporator, Heat Pipe Science and Technology, Heat Pipe Science and Technolgy An International Journal, 4(1-2), (2013) 105-117.

[46] J. Ku, L. Ottenstein, P. Rogers, K. Cheung, Investigation of Capillary Limit in a Loop Heat Pipe, in: 12th International Heat Transfer Conference, Grenoble, France, 2002.

[47] Y. Maidanik, N. Solodovnik, Y. Fershtater, Investigation of Dynamic and Stationary Characteristics of a Loop Heat Pipe, in: 9th International Heat Pipe Conference, LANL, Albuquerque, 1995, pp.1002-1006. 
[48] J. Ku, G. Birur, Capillary Limit in a Loop Heat Pipe with Dual Evaporators, SAE Paper No.2002-01-2503, 2002.

[49] A. Habtour, M. Nikitkin, Miniature Multiple Evaporator Multiple Condenser Loop Heat Pipe, in: 19th Annual AIAA/USU Conference on Small Satellites, Logan, Utah, 2005.

[50] J. Ku, L. Ottenstein, G. Birur, Thermal Performance of A Multi-Evaporator Loop Heat Pipe With Thermal Masses And Thermal Electrical Coolers, in: 13th International Heat Pipe Conference, Shanghai, China, 2004.

[51] Y. Qu, K. Zhou, K.F. Zhang, Y. Tian. Effects of Multiple Sintering Parameters on the Thermal Performance of Bi-porous Nickel Wicks in Loop Heat Pipes. International Journal of Heat and Mass Transfer, 99 (2016) 638-646.

[52] J. Ku, Loop Heat Pipe Start-up Behaviors, in: 46th International Conference on Environmental Systems, ICES-2016-24, Vienna, Austria, 2016.

[53] G. Wang, D. Mishkinis, E. MacDonald, T. Kaya, D. Nikanpour, Start-Up Performance of A Loop Heat Pipe With Variable Heating Patterns and Periodic Cycles, in: AIP Conference Proceedings, AIP, 2005, pp. 106-113.

[54] B.P. d'Entremont, Investigation of Two-Phase Behavior in Capillary Evaporators with Liquid Core Visualization, Ph. D Dissertation, Department of Mechanical Engineering, Clemson University, 2011.

[55] J. Ku, Operating Characteristics of Loop Heat Pipes, in: 29th International Conference on Enviromental System, Denver,Colorado, 1999.

[56] H. Zhang, G. Lin, T. Ding, X. Shao, R. Sudakov, Y.F. Maidanik, Experimental Study on Start-up Characteristics of Loop Heat Pipes, Science in China Series E: Technological Sciences, 48(2) (2005) 131-144.

[57] R. Riehl, T.Siqueira, Heat transport capability and compensation chamber influence in loop heat pipes performance, Applied Thermal Engineering, 26 (2006) 1158 - 1168.

[58] T.Hoang, R.Baldauff, D.Mahony, Analytical Model for Transient Loop Heat Pipe Operation, in 53rd AIAA Aerospace Sciences Meeting, Kissimmee, Florida, 2015.

[59] D.Wolf, W. Bienert, Investigation of temperature control characteristics of loop heat pipes. SAE paper, 941576, 1994.

[60] K.Cheung, T.Hoang , J. Ku, T. Kaya, Thermal performance and operational characteristics of loop heat pipe (NRL LHP). SAE paper, No.981813, 1998.

[61] S.V. Vershinin, Y.F. Maydanik, Hysteresis phenomena in loop heat pipes, Applied Thermal Engineering, 27(5) (2007) 962-968.

[62] T.Kaya, J. Ku, T.Hoang, K.Cheung, Investigation of the Temperature Hysteresis Phenomenon of a Loop Heat Pipe, in 33rd National Heat Transfer Conference, Albuquerque, NM, 1999.

[63] T. Hoang, R. Baldauff, T.Holman, J.Maxwell, Nonlinear Dynamics in Loop Heat Pipe Operation, in: 46th AIAA Thermophysics Conference, ICES-2016-24,Washington, D.C., USA, 2016.

[64] J. Li, D. Wang, G. Peterson, Experimental Studies On A High Performance Compact Loop Heat Pipe With A Square Flat Evaporator, Applied Thermal Engineering, 30(6-7) (2010) 741-752.

[65] R. Singh, A. Akbarzadeh, M. Mochizuki, Operational Characteristics Of A Miniature Loop Heat Pipe With Flat Evaporator, International Journal of Thermal Sciences, 47(11) (2008) 1504-1515.

[66] X. Zhang, J. Huo, S. Wang, Experimental investigation on temperature oscillation in a miniature loop heat pipe with flat evaporator, Experimental Thermal and Fluid Science 37 (2012) 29-36.

[67] K. Shukla, Thermo-fluid dynamics of Loop Heat Pipe operation, International Communications in Heat and Mass Transfer , 35(8) (2008) 916-920. 
[68] J. Ku, L. Ottenstein, M. Kobel, P. Rogers, T. Kaya, Temperature oscillations in loop heat pipe operation, AIP Conference Proceedings, 552(1) (2001) 255-262. 